\title{
Peroxiredoxin 6 mediates protective function of astrocytes in $A \beta$ proteostasis
}

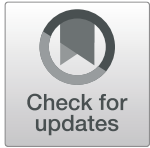

Joanna E. Pankiewicz ${ }^{1,2}$, Jenny R. Diaz ${ }^{1}$, Mitchell Martá-Ariza', Anita M. Lizińczyk¹, Leor A. Franco ${ }^{1}$ and Martin J. Sadowski ${ }^{1,2,3^{*}}$ iD

\begin{abstract}
Background: Disruption of $\beta$-amyloid (A $\beta$ ) homeostasis is the initial culprit in Alzheimer's disease (AD) pathogenesis. Astrocytes respond to emerging $A \beta$ plaques by altering their phenotype and function, yet molecular mechanisms governing astrocytic response and their precise role in countering $A \beta$ deposition remain ill-defined. Peroxiredoxin (PRDX) 6 is an enzymatic protein with independent glutathione peroxidase (Gpx) and phospholipase A2 $\left(P L A_{2}\right)$ activities involved in repair of oxidatively damaged cell membrane lipids and cellular signaling. In the CNS, PRDX6 is uniquely expressed by astrocytes and its exact function remains unexplored.
\end{abstract}

Methods: APPSWe/PS1 $1_{d E 9} A D$ transgenic mice were once crossed to mice overexpressing wild-type Prdx6 allele or to Prdx6 knock out mice. A $\beta$ pathology and associated neuritic degeneration were assessed in mice aged 10 months. Laser scanning confocal microscopy was used to characterize $A \beta$ plaque morphology and activation of plaqueassociated astrocytes and microglia. Effect of Prdx6 gene dose on plaque seeding was assessed in mice aged six months.

Results: We show that hemizygous knock in of the overexpressing Prdx6 transgene in APP swe $_{P S S 1_{d E 9}} \mathrm{AD}$ transgenic mice promotes selective enticement of astrocytes to $A \beta$ plaques and penetration of plaques by astrocytic processes along with increased number and phagocytic activation of periplaque microglia. This effects suppression of nascent plaque seeding and remodeling of mature plaques consequently curtailing brain $A \beta$ load and $A \beta$-associated neuritic degeneration. Conversely, $\operatorname{Pr} d \times 6$ haplodeficiency attenuates astro- and microglia activation around $A \beta$ plaques promoting $A \beta$ deposition and neuritic degeneration.

Conclusions: We identify here PRDX6 as an important factor regulating response of astrocytes toward A $\beta$ plaques. Demonstration that phagocytic activation of periplaque microglia vary directly with astrocytic PRDX6 expression level implies previously unappreciated astrocyte-guided microglia effect in $A \beta$ proteostasis. Our showing that upregulation of PRDX6 attenuates $A \beta$ pathology may be of therapeutic relevance for AD.

Keywords: Astrocytes, Alzheimer's disease, $\beta$-Amyloid plaques, Microglia, Neurodegeneration, Peroxiredoxin 6, Plaque seeding, Proteostasis

\footnotetext{
* Correspondence: sadowm01@med.nyu.edu

'Department of Neurology, New York University Grossman School of Medicine, 550 First Avenue, Science Building, Room 10-07, New York, NY 10016, USA

${ }^{2}$ Department of Biochemistry and Molecular Pharmacology, New York University Grossman School of Medicine, New York, NY 10016, USA Full list of author information is available at the end of the article
} 


\section{Background}

Alzheimer's disease (AD) is a progressive neurodegenerative disease, where initially occurring $\beta$-amyloid $(A \beta)$ deposition drives neurofibrillary pathology leading to synaptic and neuronal degeneration and gradual cognitive decline [1]. Containment of $A \beta$ deposition or $A \beta$ proteostasis is the initial defense mechanism preventing $A \beta$ accumulation. $A \beta$ plaques attract activated microglia, which are well recognized for their role in $A \beta$ plaque transformation and containment. Microglia phagocytose diffuse $A \beta$ peptide forming the plaque brim and compact $A \beta$ within the plaque amyloid core [2] limiting extent of $\mathrm{A} \beta$-associated neuritic degeneration [3]. ADassociated variants in Triggering Receptor Expressed in Myeloid cells 2 (TREM2) rendering microglia ineffective in $\mathrm{A} \beta$ plaque processing have been identified as second to the $A P O E \& 4$ allele genetic risk factor for sporadic $\mathrm{AD}$, highlighting the importance of periplaque glia function in $\mathrm{A} \beta$ proteostasis and in arresting downstream cascade of $\mathrm{AD}$ neurodegeneration [4]. Like microglia, activated astrocytes surround $A \beta$ plaques and penetrate the plaques with their processes. However, in contrast to microglia the role of astrocytes in $A \beta$ proteostasis and plaque formation remains ill-defined, mainly due to a paucity of known factors modulating astrocytic function in $\mathrm{AD}$, and especially those, whose variable expression level would create a tractable experimental model. In this study, we decided to explore function of astrocytes in $\mathrm{A} \beta$ proteostasis and plaque formation through modulating expression level of an astrocytic native protein peroxiredoxin (PRDX) 6. PRDX6 is a dual function enzyme with independent glutathione peroxidase (Gpx) and phospholipase A2 ( $\left.\mathrm{PLA}_{2}\right)$ activities, which is highly expressed by several cell lineages outside the CNS including alveolar epithelium, endothelium, and macrophages [5]. The PLA $\mathrm{PL}_{2}$ activity distinguishes PRDX6 from other peroxiredoxins and enables replacement of peroxidatively damaged cell membrane lipids, and cellular signaling $[6,7]$. In the CNS, PRDX6 is expressed by astrocytes but no other type of glial cells $[8,9]$ and its exact function remains largely unexplored. In normal brain, expression of PRDX6 is dormant, while in AD it becomes selectively upregulated in astrocytes, which are associated with $\mathrm{A} \beta$ plaques and neurofibrillary tangles [9]. PRDX6 does not accumulate within the plaques, thus it is a reactive but not amyloid associated protein. To explore the function of PRDX6 in A $\beta$ proteostasis we made $A P P_{s w e} / P S 1_{d E 9}$ transgenic (Tg) mice with hemizygous knock in of the overexpressing $\operatorname{Prdx} 6$ transgene and those with $\operatorname{Prdx} 6$ haplodeficiency. This experimental design showed that PRDX6 governs a protective function of astrocytes in countering $\mathrm{A} \beta$ deposition. We found an inverse dependence between $\operatorname{Prdx} 6$ gene dose and $\mathrm{A} \beta$ plaque load and plaque-associated neuritic degeneration. Prdx6 expression level also showed direct dependence with enticement of astrocytes and microglia to $A \beta$ plaques, penetration of plaques by activated astrocytes, and phagocytic activation of periplaque microglia. Since PRDX6 is an astrocytic protein, the latter observation implies that astrocytes target microglia to $A \beta$ plaques and circuitously regulate microglia dependent $A \beta$ plaque processing.

\section{Methods \\ Materials and reagents}

Primers for polymerase chain reaction protocols were synthesized to order by Sigma-Aldrich (St. Louis, MO). Synthetic $A \beta_{1-40}$ and $A \beta_{1-42}$ peptides were produced by the ERI Amyloid Laboratory LLC (Oxford, CT) and handled as previously described [10, 11]. Antibody sources are individually listed below. All chemicals and reagents, were purchased from Sigma-Aldrich unless stated otherwise.

\section{Animals}

All mouse care and experimental procedures were approved by Institutional Animal Care and Use Committees of the New York University Grossman School of Medicine. All transgenic mouse lines and C57BL/6 J wild type mice were obtained from The Jackson Laboratories (Bar Harbor, ME). APP ${ }_{\text {swe }} / P S 1_{d E 9}$ AD model mice (B6.Cg-Tg(APPswe,PSEN1dE9)85Dbo/Mmjax; stock \# 34832-JAX) express under the control of the mouse prion protein promoter the mouse amyloid precursor protein (APP) harboring the human $A \beta$ sequence with the double Swedish familial AD mutation K594M/ N595L and human presenilin 1 (PS1) with exon 9 deletion (dE9). In this model, the entire $A P P_{\text {swe }} / P S 1_{d E 9}$ transgene is transmitted as a single Mendelian locus [12, 13]. Prdx6 transgenic mice (C57BL/6 J-Tg(Prdx6)153Pgn/ Pgn; stock \#005902) overexpress the Prdx6 $6^{129 / S v J-T g}$ transgene containing the wild type Prdx6 129X1/SvJ allele, typical of the atherosclerosis-resistant 129/SvJ mouse strain, on the endogenous C57BL/6 J Prdx6 expression background [14-16]. Prdx6 knock out mice (B6.129-Prdx6tm1Pgn/Pgn; stock \#005974) feature disruption of exons 1 and 2 of the $\operatorname{Prdx} 6$ gene using a targeting vector containing the neomycin resistance and lacZ genes [17, 18]. All three transgenic mouse lines have been maintained on $\mathrm{C} 57 \mathrm{BL} / 6 \mathrm{~J}$ strain background. Hemizygous $A P P_{\text {swe }} / P S 1_{d E 9}$ mice $\left(A P P / P S 1^{1 / 0} ; \operatorname{Prd} 6^{+/+}\right)$ were mated with mice homozygous for $\operatorname{Prdx} 6^{129 / S v J-T g}$ transgene $\left(\operatorname{Prdx} 6^{+/+} / \mathrm{Tg}^{1 / 1}\right)$, wild type C57BL/6 J mice $\left(\operatorname{Prd} x 6^{+/+}\right)$, or with $\operatorname{Prdx} 6$ knock out mice $\left(\operatorname{Prdx} 6^{-/-}\right)$. This cross-breeding strategy depicted in Fig. 1a, produced the following genotypes, which were analyzed in this study: $A P P / P S 1^{1 / 0} ; \operatorname{Prd} x 6^{+/+} / \mathrm{Tg}^{1 / 0}$ (thereafter referred as $\left.A P P / P r d x 6^{T g}\right), \quad A P P / P S 1^{1 / 0} ; \operatorname{Prd} x 6^{+/+}$(thereafter 


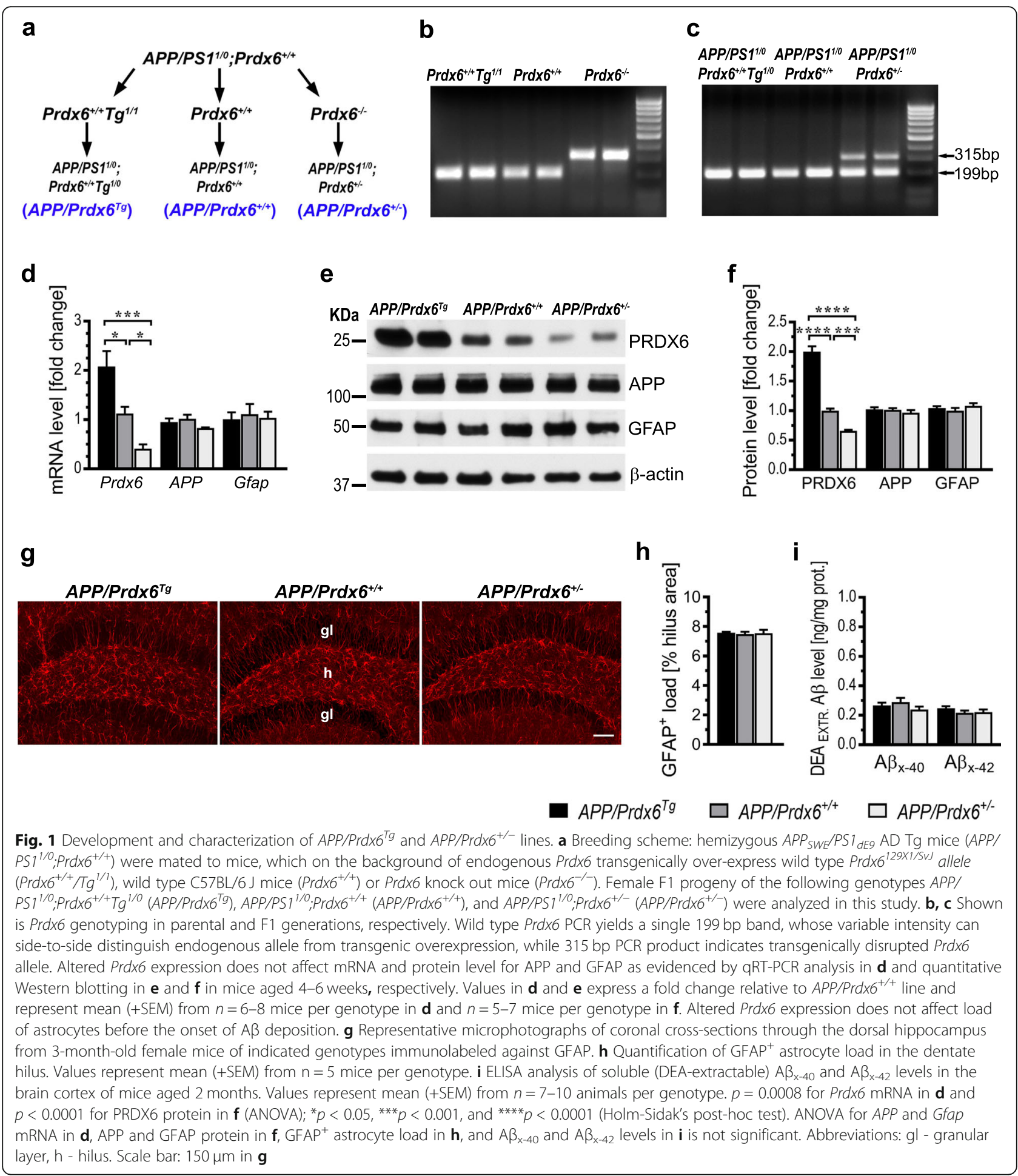

referred as $\left.A P P / P r d x 6^{+/+}\right)$, and $A P P / P S 1^{1 / 0} ; \operatorname{Prd} d x 6^{+/-}$ (thereafter referred as $A P P / \operatorname{Prd} d x 6^{+/-}$). Littermates, which did not positively genotype for the $A P P_{s w e} / P S 1_{d E 9}$ transgene, were excluded from the study. Mice separated by sex were aged to 6 or 10 months in germ free vivarium with 12-h light/dark cycle and free access to food and water. Mouse health was assessed bi-weekly following standards of good husbandry practice [19]. Each examination started with observation of animals' behavior in their home cages with attention paid to spontaneous activity, nest building, interaction with cage mates, and general appearance. This was followed by hands-on 
assessment of hydration status, postural reflexes, mobility, coat integrity, and search for subcutaneous anomalies including masses.

\section{Isolation and genotyping of genomic DNA}

Genomic DNA was obtained by tail biopsy and genotyped for $A P P_{s w e} / P S 1_{d E 9}$ and $\operatorname{Prdx6}$. Tail tissue was digested overnight at $55^{\circ} \mathrm{C}$ in the lysis buffer composed of $50 \mathrm{mM}$ Tris- $\mathrm{HCl}(\mathrm{pH} \mathrm{8.0),} 50 \mathrm{mM}$ ethylenediaminetetraacetic acid (EDTA), $50 \mathrm{mM} \mathrm{NaCl}, 0.5 \%$ of $\mathrm{N}$-Lauroyl sarcosine, $0.06 \%$ Tween 20 , and $0.5 \mathrm{mg} / \mathrm{mL}$ of Proteinase K (Roche Life Science, Indianapolis, IN). Digestion product was centrifuged at $9000 \mathrm{x}$ g for $10 \mathrm{~min}$. DNA was precipitated from resulting supernatant with 5 volumes of $100 \%$ ethanol, trice washed with $70 \%$ ethanol, and dried up in a $55^{\circ} \mathrm{C}$ heat block. DNA pellets were resuspended in $80-120 \mu \mathrm{l}$ of PCR grade $\mathrm{dH}_{2} \mathrm{O}$ and DNA concentration was photometrically determined using Nanodrop 2000 (Thermo Fisher Scientific, Waltham, MA). $A P P_{s w e} / P S 1_{d E 9}$ transgene was identified using real time polymerase chain reaction (RT-PCR) as previously described [10] on a CFX96 ${ }^{\text {tm }}$ Real-Time System (Bio-Rad Laboratories, Hercules, CA). Prdx6 DNA was amplified using specific primers forward 1: 5'-CAGGATGGAG CCTCTATGCC-3', forward 2: 5'-TGGCTTCTGA GACGGAAAGAA-3', and reverse: 5'-CTTTGAACAG AACCAGGCAGG-3' [18]. The starting amount of genomic DNA was always $500 \mathrm{ng}$. The PCR protocol was initiated by a 2 -min denaturation at $94^{\circ} \mathrm{C}$, followed by 40 amplification cycles consisting of $30 \mathrm{~s}$ denaturation at $92^{\circ} \mathrm{C}, 30 \mathrm{~s}$ annealing at $55^{\circ} \mathrm{C}$, and $30 \mathrm{~s}$ extension at $70^{\circ}$ $\mathrm{C}$, and it was concluded by the final extension step at $72^{\circ} \mathrm{C}$ for $3 \mathrm{~min}$. Amplified DNA was electrophoresisseparated on a $2 \%$ agarose gel for $60 \mathrm{~min}$, visualized with $0.5 \mu \mathrm{g} / \mathrm{ml}$ ethidium bromide and imaged using Gel Doc $\mathrm{XR}+$ (Bio-Rad Laboratories) (Fig. 1 b, c).

\section{Euthanasia and tissue handling}

Animals were euthanized with an intraperitoneal injection of sodium pentobarbital $(150 \mathrm{mg} / \mathrm{kg})$ and transcardially perfused with $10 \mathrm{mM}$ phosphate-buffered saline (PBS) (pH 7.4) with addition of heparin (1000 units/L). Immediately after perfusion brains were removed from the skulls and divided along the longitudinal fissure into left and right hemispheres. The left hemisphere was dissected under operating microscope on ice to isolate the brain cortex and the hippocampus, which were weighted, flash frozen in a dry ice/methanol cooling bath, and stored at $-80^{\circ} \mathrm{C}$ until further analyses. The right brain hemisphere was fixed by immersion in $4 \%$ paraformaldehyde diluted in $100 \mathrm{mM}$ phosphate buffer (PB) for $72 \mathrm{~h}$ at $4^{\circ} \mathrm{C}$ and stored in a mixture of $20 \%$ dimethyl sulfoxide and 20\% glycerol in 0.01 PBS (pH 7.4) at $4^{\circ} \mathrm{C}$ until sectioning and immunohistochemistry.
RNA isolation, reverse transcription, and quantitative real time PCR (qRT-PCR) analysis

RNA was extracted from the brain cortex of 4 to 6 weeks old mice immediately after their perfusion using RNeasy Mini Kit (Qiagen Sciences Inc., Germantown, MD). The RNA extract was treated with $2 \mathrm{U}$ of DNAse I (Qiagen Sciences Inc.) and its purity was assessed by electrophoresing $1 \mu \mathrm{g}$ of RNA on a $1.2 \%$ agarose gel for $60 \mathrm{~min}$, staining with $0.5 \mu \mathrm{g} / \mathrm{ml}$ of ethidium bromide and imaging using Gel Doc XR+. Five-hundred nanograms of extracted RNA were reverse transcribed into cDNA using the iScript ${ }^{\mathrm{TM}}$ Advanced cDNA Synthesis Kit (BioRad Laboratories). qRT-PCR was performed using SYBR $^{\odot}$ Green JumpStart ${ }^{\mathrm{TM}}$ Taq ReadyMix ${ }^{\mathrm{TM}}$ and the following primer sequences: 5'-TTG ATG ATA AGG GCA GGG AC-3' forward and 5' -CTA CCA TCA CGC TCT CTC CC-3' reverse for Prdx6 [18], 5'-CGA ACC CTA CGA AGA AGC CAC-3' forward and 5'-GCT TTC TGG AAA TGG GCA TGT TC-3' reverse for APP [20], 5'-GCT TTC TGG AAA TGG GCA TGT TC-3' forward and 5' -TCTGCCTCCAGCCTCAGGTT3' reverse for Gfap [21], and 5'-CCG GGG CTG GCA TTG CTC TC-3' forward and 5' -TGT TGG GGG CCG AGT TGG GA-3' reverse for murine glyceraldehyde-3phosphate dehydrogenase (Gapdh) [20]. Amplification efficiency for each primer pair was verified from the regression slope between the cDNA dilution log values and the averaged cycle threshold $\left(\mathrm{C}_{\mathrm{T}}\right)$ value obtained for each cDNA dilution. Expression of target genes: Prdx6, $A P P$, and Gfap was analyzed using $2^{-\Delta \Delta \mathrm{Ct}}$ method [22]. Firstly, $C_{\mathrm{T}}$ values for each target gene were normalized to the $C_{T}$ values for Gapdh as the reference gene for each animal individually. Resulting $\Delta C_{T}$ values were then normalized to averaged $\Delta \mathrm{C}_{\mathrm{T}}$ values for a given target gene in $A P P / P r d x 6^{+/+}$line. Target gene expression in $A P P / P r d x 6^{T g}$ and $A P P / P r d x 6^{+/-}$lines was calculated as a fold difference relative to these in $A P P / P r d x 6^{+/+}$line. qRT-PCR was performed on a CFX96 ${ }^{\mathrm{Tm}}$ Real-Time System.

\section{Western blot analysis}

Samples of the brain cortex stored at $-80^{\circ} \mathrm{C}$ were thawed, weighted, and homogenized $\left(1: 10 \mathrm{wt} / \mathrm{vol}\right.$ at $\left.4^{\circ} \mathrm{C}\right)$ in a buffer consisting of $20 \mathrm{mM}$ Tris-HCL (pH 7.4), $250 \mathrm{mM}$ sucrose, $1 \mathrm{mM}$ egtazic acid, $1 \mathrm{mM}$ EDTA and $10 \mu \mathrm{g} / \mathrm{mL}$ of a Complete Protease Inhibitor Cocktail (Roche Life Science) supplemented with $1 \mathrm{mM}$ phenylmethylsulfonyl fluoride, and leupeptin, antipain, and pepstatin $(5 \mu \mathrm{g} / \mathrm{mL}$ each). The three-step homogenization procedure included manual trituration in a pestle grinder, passing the tissue through a 28-gauge needle, and final sonication. Cellular debris were cleared by $3 \mathrm{~min}$ centrifugation at $10,000 \times \mathrm{g}$ and $4^{\circ} \mathrm{C}$ and protein concentration in the resulting supernatant was measured by bicinchoninic acid (BCA) method 
using Pierce ${ }^{\mathrm{TM}}$ BCA Protein Assay Kit (Thermo Fisher Scientific), according to the manufacturer provided manual. Aliquots of brain homogenates containing $20 \mu \mathrm{g}$ of the total protein for PRDX6 and APP and $5 \mu \mathrm{g}$ for GFAP and $\beta$-actin were resolved on $10 \%$ SDS-PAGE and electroblotted onto nitrocellulose membranes, which were then blocked with $5 \%$ nonfat milk and incubated with the following primary antibodies anti-PRDX6 (rabbit polyclonal 1:10,000; Abcam Inc., Cambridge, MA), anti-GFAP (rabbit polyclonal 1:10,000; DAKO, Denmark), anti-APP (mouse monoclonal, clone C1/6.1 1:3000; BioLegend, San Diego, $\mathrm{CA}$ ), and anti- $\beta$-actin (mouse monoclonal 1:10,000, Sigma-Aldrich). The antigen-antibody complexes were detected using horseradish peroxidase conjugated sheep anti-mouse or anti-rabbit secondary antibodies (1:30,000; GE Healthcare Bio-Sciences Corp. Pittsburgh, PA) and visualized using SuperSignal West Pico PLUS Chemiluminescent Substrates (Thermo Fisher Scientific). Resulting autoradiograph were digitized into a 600 dpi TIFF files and analyzed using NIH Image J1.52a software (Bethesda, MD).

\section{Biochemical analyses of $A \beta_{x-40}$ and $A \beta_{x-42}$ levels}

Samples of brain cortex homogenate were prepared analogously to those for the Western blot analysis and subjected to diethylamine (DEA) or formic acid (FA) extractions $[23,24]$, which release soluble or total $A \beta$ peptides, respectively. Concentration of $\mathrm{A} \beta_{\mathrm{x}}-40$ and $\mathrm{A} \beta_{\mathrm{x}-42}$ in either fraction was determined on ELISA plates coated with HJ2 (anti-A $\beta_{35-40}$ ) or HJ7.4 (anti-A $\beta_{37-42}$ ) mouse monoclonal antibodies $(0.5 \mu \mathrm{g} /$ well; gift of $\mathrm{Dr}$. DM Holtzman), respectively [20, 25]. Biotinylated 4G8 mouse monoclonal antibody (anti-A $\beta_{17-24}, 1: 5000$; BioLegend) [26] was used as the detection antibody. Optic densities of ELISA readouts were converted to the actual concentrations of $A \beta$ peptides based on the standard curves prepared from FA-treated synthetic $A \beta_{1-40}$ and $\mathrm{A} \beta_{1-42}$ peptides. Final $A \beta_{x-40}$ and $A \beta_{x-42}$ concentrations in the brain tissue were reported in reference to the protein concentration considering all dilutions made during DEA and FA extractions [25].

\section{Histology and immunohistochemistry}

The right brain hemisphere was serially sectioned into coronal $40-\mu \mathrm{m}$-thick sections using a freezing microtome (Leica Microsystems, Wetzlar, Germany). The sections were alternately collected into 10 series, then randomly selected for the following stainings: 1) Thioflavin-S (ThS), 2) anti-A $\beta$ (mouse monoclonal HJ3.4 directed against the N-terminus of $A \beta, 1: 100$; gift of Dr. DM Holtzman) [20, 25, 27]; 3) anti-GFAP (mouse monoclonal 1:2000; Sigma-Aldrich); 4) anti-Iba1 (rabbit polyclonal 1:1000; Wako Chemicals Inc., Richmond VA); 5) anti-CD68 (rabbit polyclonal 1:200, Abcam Inc.,
Cambridge, MA), and 6) Gallyas silver staining. For the anti-A $\beta$ immunostaining the sections were pretreated with $44 \%$ FA for $10 \mathrm{~min}$ to enhance antigen availability [25] and the immunohistochemistry protocol was conducted using peroxidase M.O.M. and 3,3' -diaminobenzidine kits from Vector Laboratories (Burlingame, CA) as per manufacturer manual. For anti-GFAP immunostaining biotinylated horse-anti mouse IgG secondary antibody (1:500; Vector Laboratories) was used, while for anti-CD68 and anti-Iba1 immunostainings the secondary antibody was biotinylated goat anti-rabbit IgG (1:500; Vector Laboratories). The immunostaining protocol was concluded with streptavidin conjugated Cy3 fluorochrome (1:1000; Vector Laboratories) and Th-S counterstaining to visualize relationship between glial cells and fibrillar plaques as previously described [27]. Gallyas silver staining was carried out at $10^{\circ} \mathrm{C}$ and it was modified from its original protocol $[26,28]$ by extending the time of alkaline silver iodide enucleation to $40 \mathrm{~min}$.

Specifically, for this project we developed several multi-fluorochrome labeling protocols to interrogate the relationship between $\mathrm{A} \beta$ plaques and plaque-associated glia cells. The fibrillar plaque core was labeled first with $\mathrm{X}-34(10 \mu \mathrm{M}$ in $40 \%$ ethanol [pH 10]) and then various glial antigens were immunostained with one of the following antibodies: anti-GFAP (rabbit polyclonal 1:2000; Dako/Agilent Technologies; Santa Clara, CA), anti-Iba1 (rabbit polyclonal 1:800; Wako Chemicals USA Inc.) or anti-CD68 (rat monoclonal 1:200; Abcam Inc.). Prior to applying the primary antibody, non-specific staining was blocked with a mixture of $10 \%$ normal goat serum, $1 \%$ bovine serum albumin (BSA), and $0.3 \%$ Triton X-100 in $10 \mathrm{mM}$ PBS (pH 7.4) and in the case of anti-CD68 immunostaining additionally Avidin/Biotin Blocking Kit (Vector Laboratories) was used as per manufacturer manual. The secondary antibodies were Texas Red conjugated goat anti-rabbit IgG (1:500; Vector Laboratories) or goat biotinylated anti-rat IgG (1:500; Abcam Inc.) followed by Cy3 conjugated streptavidin (1:500). Subsequently, we immunolabelled the diffuse (non-fibrillar) $\mathrm{A} \beta$ within the plaque brim with $\mathrm{HJ} 3.4$ mouse monoclonal antibody (1:100; gift of Dr. D.M. Holtzman) followed by Dylight 488 conjugated horse anti-mouse IgG secondary antibody (1:500; Vector Laboratories). Cell nuclei were optionally stained with $1 \mu \mathrm{M}$ of DRAQ5 (Thermo Fisher Scientific) as the fourth and the final step of the protocol.

For TREM2 visualization the sections were first pretreated with $10 \mathrm{mM}$ sodium citrate and $0.5 \%$ Tween 20 ( $\mathrm{pH} \mathrm{6.0)} \mathrm{for} 20 \mathrm{~min}$ at $85^{\circ} \mathrm{C}$ to help the antigen retrieval [29]. Following labeling of the fibrillar plaque core with X-34, non-specific immunostaining was blocked with $5 \%$ normal donkey serum (Jackson ImmunoResearch, West Grove, PA) and $0.3 \%$ Triton X-100. The primary 
antibodies were anti-TREM2 (sheep polyclonal 1:250; R\&D Systems, Minneapolis MN) and anti-Iba1 (rabbit polyclonal 1:1000; Wako Chemicals Inc.), while the secondary antibodies were donkey anti-sheep Alexa Fluor 594 conjugated (1:500; Thermo Scientific Scientific) and donkey anti-rabbit Alexa Fluor 488 conjugated (1:500; Jackson ImmunoResearch) both diluted in $4 \%$ normal donkey serum and $0.3 \%$ Triton, respectively. For analysis of cellular localization of PRDX6, the sodium citrate antigen retrieval protocol was used too. The primary antibodies were either anti-GFAP (mouse monoclonal 1: 1,500; Sigma-Aldrich) or anti-Iba1 (mouse monoclonal 1:100; Sigma-Aldrich) and anti-PRDX6 (rabbit polyclonal 1:250; Abcam Inc.), while the secondary antibodies were goat anti-mouse Alexa Fluor 488 conjugated (1:500; Jackson ImmunoResearch) and goat anti-rabbit Alexa Fluor 594 conjugated (1:500; Jackson ImmunoResearch), respectively. For analysis of $A \beta$ plaqueassociated axonal dystrophy antigen retrieval with sodium citrate was used as well. The primary antibodies were anti- $\mathrm{A} \beta_{1-16}$ (rabbit polyclonal 1:500; BioLegend) and anti-Neurofilament (mouse monoclonal [clone SIM 312] 1:300; BioLegend), while the secondary antibodies were goat anti-rabbit Alexa Fluor 488 conjugated (1:500; Jackson ImmunoResearch) and goat anti-mouse Alexa Fluor 594 conjugated (1:500; Jackson ImmunoResearch), respectively.

\section{Quantitative analysis of $A \beta$ plaque load and that of astrocytes and microglia}

The load is defined as the percentage of a crosssectional profile covered by positively-thresholded objects. It was determined using whole-section approach, where the entire cross-sectional profile of a given anatomical structure is digitally photographed and thresholded to prevents sampling bias [27]. We quantified the load of Th-S labeled fibrillar $A \beta$ plaques and that of HJ3.4 immunostained $A \beta$ plaques both in the brain cortex and in the hippocampus and loads of $\mathrm{GFAP}^{+}$astrocytes and $\mathrm{Iba}^{+}$and $\mathrm{CD}^{+} 8^{+}$microglia in the brain cortex. Cortical load was analyzed on 3 coronal sections per brain taken at the approximated levels of the anterior commissure, the rostral portion of the hippocampus, and the mammillary bodies, while the hippocampal load was analyzed on $4-5$ serial sections spaced $800 \mu \mathrm{m}$ apart. Load values obtained from individual cortical and hippocampal profiles were averaged for each brain. Infrequent Th-S or anti-A $\beta$ positive vascular profiles were edited out from digitized images. Sections immunolabelled for GFAP, Iba1 and CD68 also were counterstained with Th-S and the glia cell load was indexed to that of Th- $\mathrm{S}^{+}$ plaques on the same section. All load analyses were performed using NIH ImageJ v1.52. In addition, the load of $\mathrm{GFAP}^{+}$cells was quantified in the dentate hilus in mice aged 2 months before the onset of $\mathrm{A} \beta$ deposition to assess for differences resulting from variable Prdx6 expression. Numerical density of neuritic plaques was determined by taking their count on 3 cortical and 4-5 hippocampal profiles per brain on Gallyas stained sections and dividing obtained count by combined area of cross-sectional profiles. Similarly, we quantified the numerical density of nascent plaques in the brain cortex of mice aged 6 months.

\section{Laser scanning confocal microscopy (LSCM) and segmentation analysis of $A \beta$ plaques}

Images of multi-fluorochrome labeled $A \beta$ plaques were taken under immersion oil, 63x, and 1.4 N.A. objective and 2x digital zoom using Zeiss LSM 880 microscope and ZEN Black 2.3 SP1 acquisition software v. 14.0.18.201 (Carl Zeiss AG; Oberkochen, Germany). Z stacks of $0.5-\mu \mathrm{m}$-thick serial tomograms with $25 \%$ overlap (increased to $50 \%$ for TREM2 imaging) were acquired through the entire thickness of $A \beta$ plaques. For morphometric analysis 8 serial tomograms (or 12 for TREM2 imaging) dissecting through the center of the plaque fibrillar core were taken out from the original Zstack and collapsed into a 2D image. Monochromatic images of individual plaque labels were then converted to 8-bit format, contrast enhanced, and analyzed using NIH ImageJ v1.52 (Fig. S1a-c). The following metrics of $A \beta$ plaques were analyzed: 1 ) plaque area (the crosssectional area of $A \beta$ plaque implicit within the outline of HJ3.4 immunolabel [Fig. S1b]), 2) plaque/core ratio (ratio between the plaque area and the area of its X-34 $4^{+}$fibrillar core), 3) GFAP plaque index $\left(\mathrm{GFAP}^{+} \%\right.$ plaque area) (Fig. S1c), 4) density of plaque-associated microglia (number of $\mathrm{Iba}^{+}$microglia cells implicit within the $\mathrm{A} \beta$ plaque outline divided by the outline area), 5) Iba1 plaque index (Iba1 ${ }^{+} \%$ plaque area), 6) microglia barrier robustness index (Iba1/X-34\% co-localization), 7) CD68 phagosome plaque index $\left(\mathrm{CD}^{+} 8^{+} \%\right.$ plaque area), 8$)$ TREM2 plaque area (TREM2 ${ }^{+} \%$ area within the $40 \mu \mathrm{m}$ radius from the plaque center), 9) TREM2 to Iba1 ratio in plaque-associated microglia, 10) number of NFpositive swellings per plaque, and 11) NF plaque index $\left(\mathrm{NF}^{+} \%\right.$ plaque area).

\section{Statistical analysis}

Normal distribution of data was confirmed first using the Kolmogorov-Smirnov and Shapiro-Wilk tests. Differences across multiple data sets were analyzed using oneway analysis of variance (ANOVA) followed by HolmSidak's multiple comparison test to ascertain significance between individual data set pairs. Statistical analysis was performed using GraphPad Prism v 7.03 (GraphPad Software Inc. San Diego, CA). All data presented in the manuscript are given as the mean and the standard error 
of the mean (SEM). Magnitude of change across genotypes was always expressed as the percentage value for $A P P / P r d x 6^{+/+}$mice, or as a fold-change when direct comparison between $A P P / P r d x 6^{T g}$ and $A P P / P r d x 6^{+/}$genotypes was made.

\section{Results \\ Overexpression of Prdx6 reduces $A \beta$ load while $\operatorname{Prdx} 6$ haplodeficiency increases it}

To differentially express Prdx6 we crossed APP $P_{S W E}$ $P S 1_{d E 9}\left(A P P / P r d x 6^{+/+}\right)$AD Tg model mice $[12,13]$ with mice transgenically over-expressing $\operatorname{Prd} x 6^{129 X 1 / S v J}$ allele on the wild-type $\operatorname{Prdx} 6$ background $\left(\operatorname{Prdx} 6^{+/+} / \mathrm{Tg}^{1 / 1}\right)$ [15] or with $\operatorname{Prdx6}$ knock out $\left(\operatorname{Prdx} 6^{-/-}\right)$mice [18]. Resulting lines were termed $A P P / P r d x 6^{T g}$ and $A P P / P r d x 6^{+/-}$, respectively (Fig. 1a-c); and exhibited no phenotypical or gross behavioral defects or precocious morbidity compared to parental APP/Prdx $6^{+/+}$mice. Levels of $\operatorname{Prdx} 6$ mRNA and PRDX6 protein in the brain cortex of mice aged 4-6 weeks show 2:1:0.6 ratio across $A P P / P r d x 6^{T g}$, $A P P / P r d x 6^{+/+}$, and $A P P / P r d x 6^{+/-}$genotypes, while the expression of APP and GFAP remain unchanged both by mRNA and protein analysis (Fig. 1d-f). Likewise, we found no differences in the morphology of $\mathrm{GFAP}^{+}$astrocytes and their load in the dentate hilus, which we analyzed in mice aged 3 months (Fig. 1g, h). Soluble $A \beta_{x-40}$ and $A \beta_{x-42}$ peptides were extracted using diethyalamine [DEA] from the brain cortex of mice aged 2 months and quantified using C-terminus specific ELISAs and their levels showed no significant differences across the genotypes (Fig. 1i). These data evidence that alteration of $\operatorname{Prdx} 6$ gene expression does not affect resting state of astrocytes or brain $A \beta$ levels prior to the onset of plaque formation.

The effect of Prdx6 gene dose on A $\beta$ deposition was detailed in female mice aged 10 months. APP/Prdx $6^{T g}$ line shows $21 \%$ reduction in the fibrillar $\left(\mathrm{Th}-\mathrm{S}^{+}\right) \mathrm{A} \beta$ plaque load in the brain cortex $(p<0.0001)$ and $26 \%$ reduction in the hippocampus $(p<0.0001)$ compared to $A P P / P r d x 6^{+/+}$controls, while conversely APP/Prd $x 6^{+/-}$ mice demonstrate $28 \%(p<0.0001)$ and $22 \%(p<0.001)$ increase in respective structures (Fig. 2a, b). The load of immunolabeled $A \beta$ plaques shows $22 \%$ reduction in the brain cortex $(p<0.0001)$ and $17 \%$ reduction in the hippocampus $(p<0.01)$ in $A P P / P r d x 6^{T g}$ mice compared to $A P P / P r d x 6^{+/+}$controls, while in $A P P / P r d x 6^{+/-}$mice it is increased by $32 \%(p<0.0001)$ and $80 \%(p<0.0001)$ (Fig. 2c, d), respectively. In direct comparison with APP/ $\operatorname{Prd} x 6^{T g}$ line, APP $/ P r d x 6^{+/-}$mice show 1.6-fold higher load of fibrillar $A \beta$ plaques both in the brain cortex and in the hippocampus $(p<0.0001)$, while the load of immunolabeled $\mathrm{A} \beta$ plaque is 1.7 -fold higher in the cortex $(p<0.0001)$ and 2.2-fold higher in the hippocampus $(p<0.0001)$.
Levels of soluble and total deposited $A \beta_{x-40}$ and $A \beta_{x-42}$ were quantified in DEA and FA brain cortex extracts, respectively. In $A P P / P r d x 6^{T g}$ mice soluble $\mathrm{A} \beta_{\mathrm{x}-40}$ and $\mathrm{A} \beta_{\mathrm{x}-42}$ levels are reduced by $35 \%(p=0.18)$ and $45 \%$ $(p<0.05)$ compared to APP/Prdx $6^{+/+}$controls, respectively; while in $A P P / P r d x 6^{+/-}$mice they are increased by $156 \%(p<0.0001)$ and $28 \%(p=0.09)$, respectively (Fig. $2 e)$. Total $A \beta_{x-40}$ and $A \beta_{x-42}$ levels are reduced by $26 \%$ $(p<0.01)$ and $22 \%(p<0.01)$ in $A P P / P r d x 6^{T g}$ mice compared to $A P P / P r d x 6^{+/+}$controls, respectively; while in $A P P / P r d x 6^{+/-}$mice they are increased by $20 \%(p<0.01)$ and $18 \%(p<0.05)$, respectively (Fig. 2f). In direct comparison with $A P P / \operatorname{Pr} d x 6^{T g}$ line, APP $/ \operatorname{Pr} d x 6^{+/-}$mice show 3 -fold $(p<0.0001)$ and 1.3-fold $(p<0.01)$ higher levels of soluble $A \beta_{x-40}$ and $A \beta_{x-42}$, respectively; and 1.6-fold $(p<0.0001)$ and 1.5-fold $(p<0.01)$ higher levels of total $\mathrm{A} \beta_{\mathrm{x}-40}$ and $\mathrm{A} \beta_{\mathrm{x}-42}$, respectively. Of note, Prdx6 haplodeficiency effects an increase in $A \beta$ accumulation in $A D$ Tg mice comparable to that caused by Trem 2 haplodeficiency or Trem $2 \mathrm{R} 47 \mathrm{H}$ mutant, conferring loss of TREM2 function [29].

To examine whether the effect of $\operatorname{Prdx} 6$ gene dose on $A \beta$ deposition is gender-specific, we compared $A \beta$ plaque load in female and male littermates at the age of 10 months (Fig. S1 a-d). Significant reduction in $\mathrm{A} \beta$ plaque load in $A P P / \operatorname{Prdx} 6^{T g}$ line and its increase in $A P P / P r d x 6^{+/-}$line compared to $A P P / P r d x 6^{+/+}$controls is evident in both sexes. When matched for $\operatorname{Prdx} 6$ genotype, female mice show significantly higher load of plaques than male mice, irrespective of plaque type and brain structure analyzed. This latter observation is consistent with reports indicating gender-based disparity in $A \beta$ plaque load in some of $\mathrm{AD} T \mathrm{Tg}$ mouse models, with propensity toward greater $A \beta$ accumulation in females [30, 31]. All further analyses presented in this study were performed on female mice to assure gender consistence.

\section{Prdx6 gene dose does not influence $A \beta$-associated astrocytic load but has a direct relationship with that of microglia}

To gain insight into the mechanism(s) underlying opposing relationship between $\operatorname{Prd} \alpha 6$ gene dose and A $\beta$ deposition and inform design of subsequent experiments we quantified loads of $\mathrm{GFAP}^{+}$astrocytes and $\mathrm{Ibal}^{+}$and $\mathrm{CD}^{+} 8^{+}$microglia in the cortex of female mice aged 10 months and indexed them to the load of fibrillar $\left(\mathrm{Th}-\mathrm{S}^{+}\right)$ $\mathrm{A} \beta$ plaques. The unindexed $\mathrm{GFAP}^{+}$load in $A P P / \operatorname{Pr} d x 6^{T g}$ mice shows $12 \%(p<0.0001)$ reduction, while in APP/ $\operatorname{Prd} x 6^{+/-}$mice $15 \%$ increase $(p<0.0001)$ compared to $A P P / P r d x 6^{+/+}$controls (Fig. 3a, b). The differences across genotypes equalize and become statistically insignificant when GFAP $^{+}$load is indexed to that of $\mathrm{Th}^{+} \mathrm{S}^{+}$ 

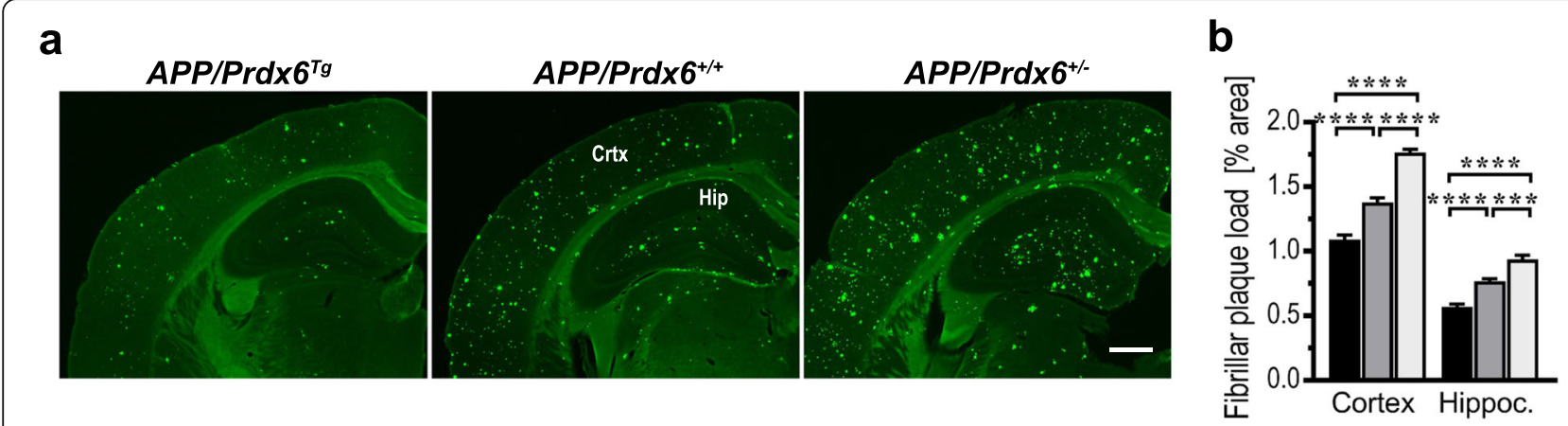

C
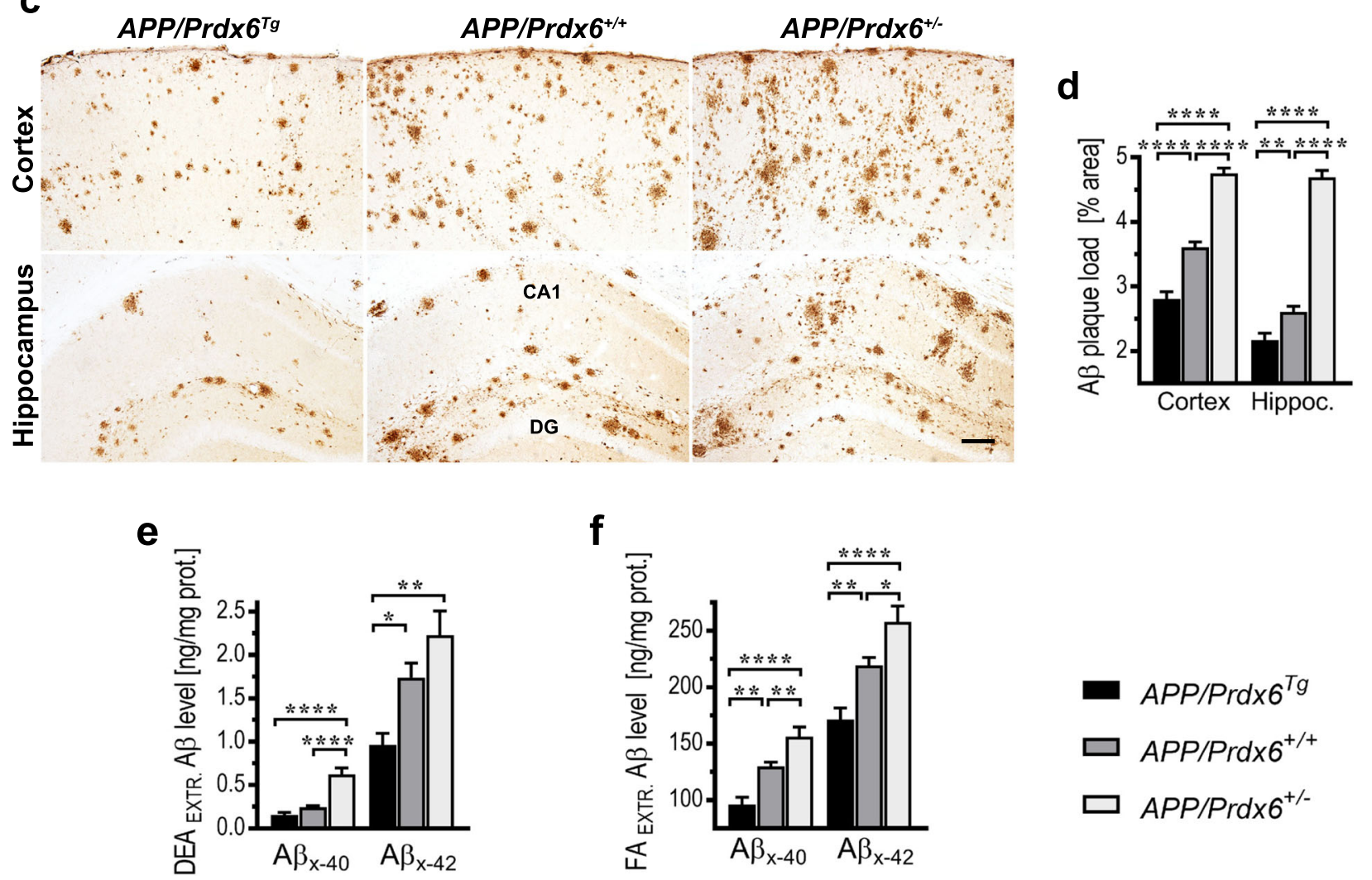

Fig. $2 \mathrm{~A} \beta$ load in APP $\mathrm{SWE}_{\mathrm{PS}} / \mathrm{dEg}$ mice varies inversely with Prdx6 gene expression level. a and $\mathbf{c}$ Representative microphotographs of coronal cross-sections through the somatosensory cortex and the dorsal hippocampus from 10-month-old female mice of indicated genotypes, which were stained for fibrillar A $\beta$ plaques with Thioflavin-S or immunolabeled with HJ3.4 clone directed against the N-terminus of A $\beta$ peptide, respectively. Quantitative analysis of fibrillar $\mathbf{b}$ and immunopositive $\mathbf{d} A \beta$ plaque load in the brain cortex and in the hippocampus evidencing suppression of $A \beta$ deposition in Prdx6 overexpressing mice and increased $A \beta$ deposition in $\operatorname{Pr} d \times 6$ haplodeficient mice. Values represent mean (+SEM) from $n=9-12$ female mice per genotype. $\mathbf{e}$ and $\mathbf{f}$ ELISA analysis of soluble (DEA-extractable) and total (FA-extractable) $A \beta_{x-40}$ and $A \beta_{x-42}$ levels in the brain cortex of female 10-month-old mice, respectively. Values represent mean (+SEM) from $n=7-13$ animals per genotype. $p<0.0001$ in $\mathbf{b}, \mathbf{d}$, e, and $\mathbf{f}$ (ANOVA); ${ }^{*} p<0.05,{ }^{* *} p<0.01,{ }^{* * *} p<0.001$, and ${ }^{* * * *} p<0.0001$ (Holm-Sidak's post-hoc test). Abbreviations: CA1 cornu Ammonis sector 1, Crtx - cortex, DG - dentate gyrus, Hip - hippocampus. Scale bars: $750 \mu \mathrm{m}$ in a and $50 \mu \mathrm{m}$ in c

plaques (Fig. 3c). Unindexed loads of $\mathrm{Iba1}^{+}$and $\mathrm{CD} 68^{+}$ microglia vary only modestly across the genotypes: with $5 \%$ reduction $(p<0.05)$ in the $\mathrm{Iba}^{+}$load in APP/ Prd $x 6^{+/-}$mice vs. APP $/ \operatorname{Prd} x 6^{+/+}$controls (Fig. 3d, e), and $16 \%$ increase $(p<0.0001)$ in the $\mathrm{CD}^{+} 8^{+}$load in $A P P / P r d x 6^{T g}$ mice vs. APP/Prdx6 $6^{+/+}$controls (Fig. 3g, h). However, when either $\mathrm{Iba1}^{+}$or $\mathrm{CD} 68^{+}$load becomes indexed to that of $\mathrm{Th}-\mathrm{S}^{+}$plaques, a strong gradient of microglia activation across the three genotypes emerges: $A P P / P r d x 6^{T g}>A P P / P r d x 6^{+/+}>A P P / P r d x 6^{+/-}$(Fig. 3f, i). The $\mathrm{Th}^{-\mathrm{S}^{+}}$indexed $\mathrm{Ibal}^{+}$load is increased by $16 \%$ $(p<0.0001)$ in $A P P / P r d x 6^{T g}$ mice, while in APP/ 


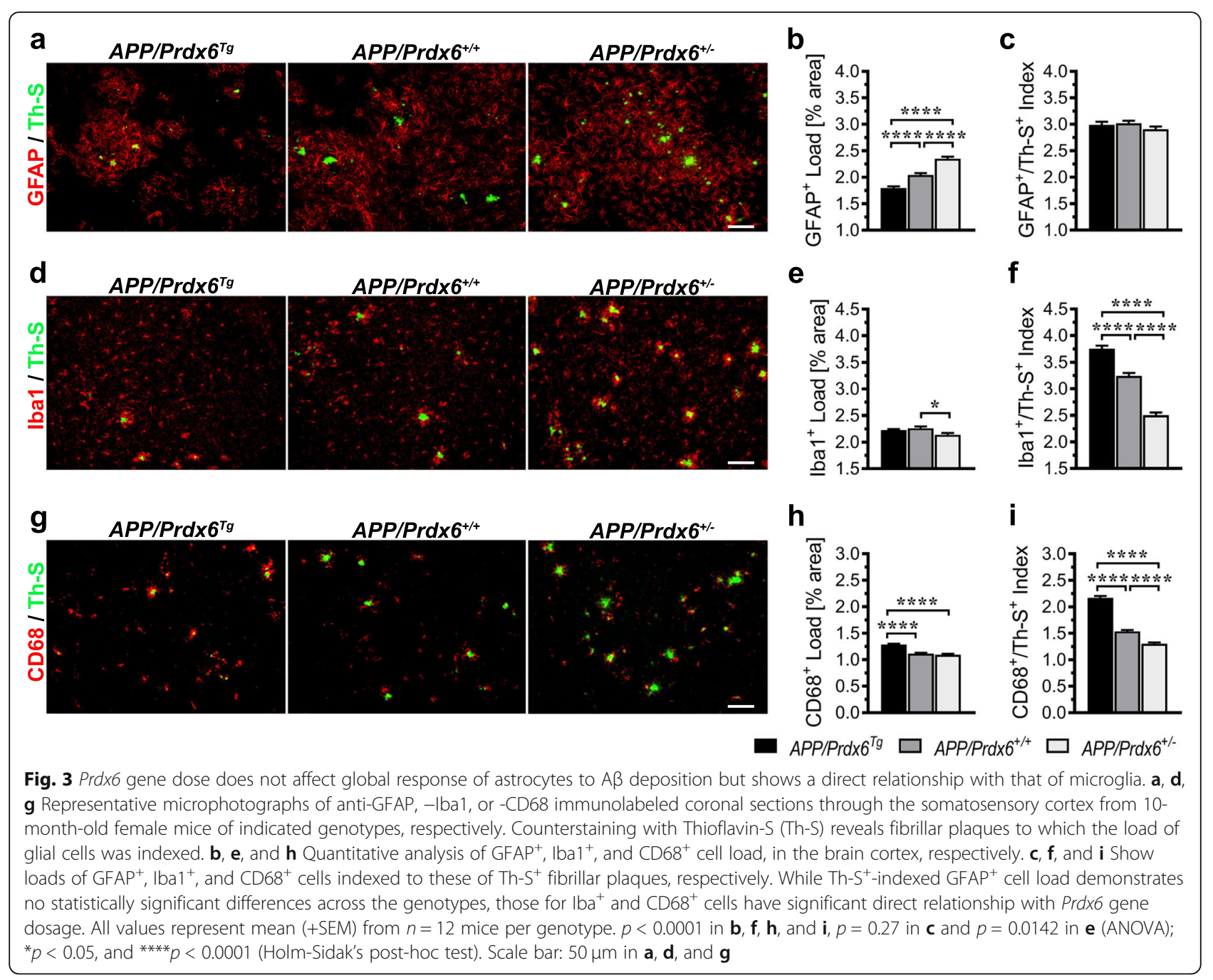

$\operatorname{Prdx} 6^{+/-}$mice it is reduced by $23 \%(p<0.0001)$ compared to $A P P / P r d x 6^{+/+}$controls. Analogously, the Th-S $\mathrm{S}^{+}$ indexed $\mathrm{CD}^{+} 8^{+}$load is increased by $41 \%(p<0.0001)$ in $A P P / \operatorname{Prd} x 6^{T g}$ mice and reduced by $15 \%(p<0.0001)$ in $A P P / P r d x 6^{+/-}$mice compared to APP/Prd $x 6^{+/+}$controls. In direct comparison with $A P P / P r d x 6^{T g}$ line, APP/ $\operatorname{Prdx} 6^{+/-}$mice show 1.5 -fold $(p<0.0001)$ and 1.7 -fold $(p<0.0001)$ reduction in the loads of $\mathrm{Iba}^{+}$and $\mathrm{CD}^{+} 8^{+}$ microglia cells, when these are indexed to that of Th$\mathrm{S}^{+}$plaques. These findings collectively indicate that neither Prdx6 overexpression effects hyperactive astrogliosis nor Prdx6 haplodeficiency impairs ability of astrocytes to mount response to $A \beta$ deposition since the $\mathrm{GFAP}^{+}$load remains proportional to that of fibrillar amyloid deposits across the three genotypes. Unexpectedly, we find that activation of microglia varies directly with the Prdx6 gene dose and this includes CD68 antigen expression, which reflects phagocytic microglia activity.
Prdx6 overexpression and haplodeficiency produce opposite effects on $A \beta$ plaque modeling by plaqueassociated astrocytes and microglia

We used multi-antigen labeling and laser scanning confocal microscopy (LSCM) to analyze effects of Prdx6 gene dose on the morphology of $\mathrm{A} \beta$ plaques and behavior of plaque-associated glial cells (Fig. S2 a-c). In APP/ $\operatorname{Prd} x 6^{T g}$ mice, the average plaque area (i.e. area implicit within the outline of anti-A $\beta$ label) is reduced by $18 \%$ $(p<0.01)$ compared to APP/Prdx $6^{+/+}$controls, while the ratio of plaque area to the area of its $\mathrm{X}-34^{+}$fibrillar core (plaque/core ratio) is reduced by $17 \%(p<0.01)$ evidencing increased plaque compactness (Fig. $4 \mathrm{a}-\mathrm{c}$ ). Opposite effects are seen in APP/Prd $x 6^{+/-}$mice, where the average plaque area and the plaque/core ratio are increased by $39 \%(p<0.0001)$ and $16 \%(p<0.01)$ compared to $A P P / P r d x 6^{+/+}$controls, respectively. In direct comparison with $A P P / P r d x 6^{T g}$ line, in $\mathrm{APP} / \operatorname{Prd} x 6^{+/-}$mice an average $\mathrm{A} \beta$ plaque area is 1.7 -fold bigger $(p<0.0001)$ 

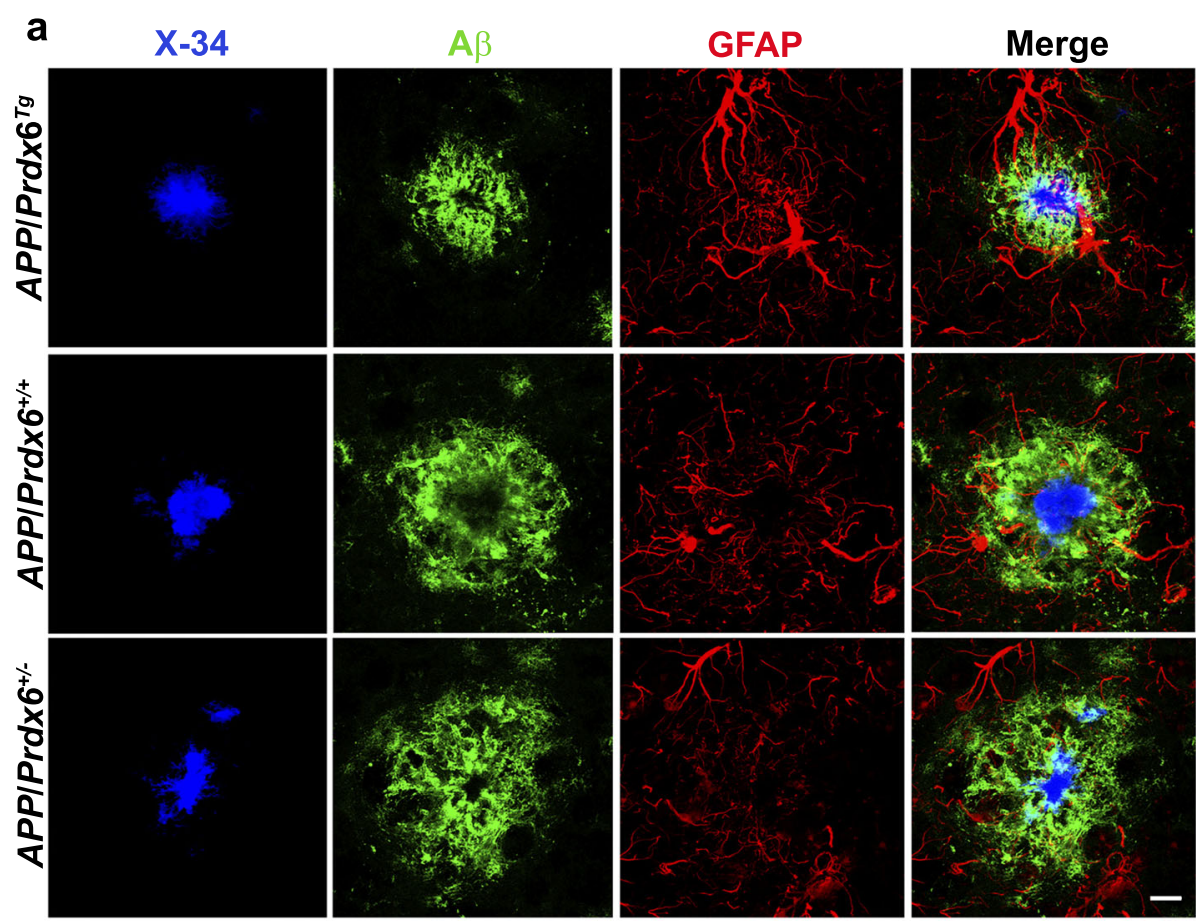

b

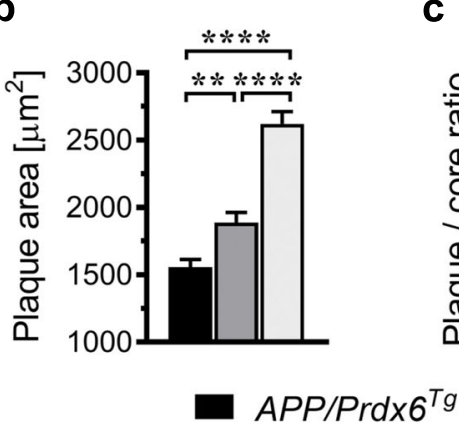

C

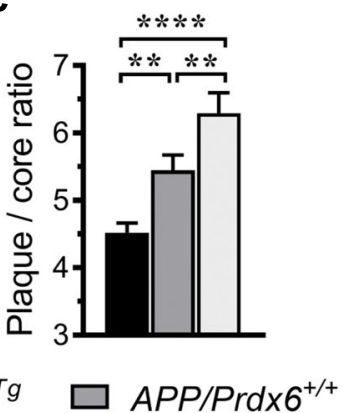

d

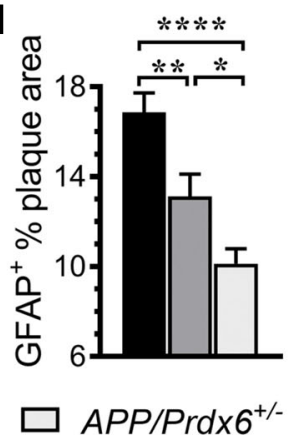

Fig. 4 Prdx6 expression alters plaque morphology and their penetrance by astrocytes. a Representative LSCM images of mature plaques triple labeled with X-34 (fibrillar core), anti-Aß (HJ3.4 clone), and anti-GFAP antibodies from female mice of indicated genotypes demonstrating inverse relationship between $\operatorname{Pr} d \times 6$ gene dose and size of $A \beta$ plaques and degree of plaque compactness expressed as a ratio between cross-sectional areas of $A \beta$ plaque label and X-34 labeled fibrillar core. Prdx6 overexpression also is associated with increased penetrance of $A \beta$ plaques by astrocytes, while in Prdx6 haplodeficient mice the number and caliber of plaque penetrating GFAP positive processes are diminished. Shown are quantitative analyses of: average A $\beta$ plaque cross-sectional area $\mathbf{b}$, plaque/core ratio $\mathbf{c}$, and GFAP plaque index (GFAP $\%$ plaque area) $\mathbf{d}$. Values in $\mathbf{b}$ and $\mathbf{c}$ represent mean (+SEM) from $n=70-90$ randomly selected plaques per genotype, while those in $\mathbf{d}$ from $n=30$ randomly selected plaques per genotype. $p<0.0001$ in $\mathbf{b}$, $\mathbf{c}$, and $\mathbf{d}$ (ANOVA); ${ }^{*} p<0.05,{ }^{* *} p<0.01$, and ${ }^{* * *} p<0.0001$ (Holm-Sidak's post-hoc test). Scale bar: $10 \mu m$ in $\mathbf{a}$

and has 1.4-fold higher $(p<0.0001)$ plaque/core ratio. These changes in A $\beta$ plaque morphology are closely associated with differential behavior of plaque-associated astrocytes and microglia discernible across the genotypes. In $A P P / \operatorname{Prdx} 6^{T g}$ mice, there is increased infiltration of $\mathrm{A} \beta$ plaques by $\mathrm{GFAP}^{+}$astrocytic processes, reflected by $28 \%$ increase in the GFAP plaque index $\left(\mathrm{GFAP}^{+} \%\right.$ plaque area) vs. $A P P / P r d x 6^{+/+}$controls (Fig. $4 \mathrm{a}, \mathrm{d}$ ). Conversely, in APP/ $\operatorname{Prd} x 6^{+/-}$mice $\mathrm{A} \beta$ plaques are characterized by rarefaction of astrocytic processes and show $23 \%$ reduction $(p<0.05)$ in the GFAP plaque index vs. $A P P / P r d x 6^{+/+}$controls. In direct comparison with $A P P / P r d x 6^{T g}$ line, the GFAP plaque index in APP $/ \mathrm{Prdx}_{6} 6^{+-}$mice is reduced by 1.7 -fold $(p<0.001)$. These observations evidence that Prdx6 gene dose alters the way astrocytes engage $A \beta$ plaques, rather than produces global effect on the astrocytic activation in response to $A \beta$ deposition. In addition, we analyzed plaque content of apolipoprotein (apo) E, which in the CNS is produced by astrocytes and co-deposited with $A \beta$ in the plaques [32]. In $A P P / P r d x 6^{T g}$ mice, there is $41 \%$ 
increase $(p<0.0001)$ in the apoE plaque index $\left(\mathrm{ApoE}^{+} \%\right.$ plaque area) compared to APP/Prdx $6^{+/+}$controls, while in $A P P / P r d x 6^{+/-}$mice that index is reduced by $26 \%$ $(p<0.0001)$ (Fig. S3 a, b). In direct comparison with APP/ $P r d x 6^{+-}$line, APP/Prdx $6^{T g}$ mice show 1.9-fold higher $(p<0.0001)$ apoE plaque index reflecting increased engagement of $A \beta$ plaques by astrocytes. We also assessed expression of complement component 3 (C3) by astrocytes engaging $\mathrm{A} \beta$ plaques by measuring the $\mathrm{C}^{+} / \mathrm{GFAP}^{+}$ plaque index (Fig. S4 a, b). This was done because elevated C3 expression is considered a marker of the neurotoxic astrocytic phenotype also known as $\mathrm{A} 1$ [33-35]. In APP/ $\operatorname{Prdx} 6^{T g}$ mice the $\mathrm{C}^{+} / \mathrm{GFAP}^{+}$index is reduced by $26.7 \%$ compared to $A P P / P r d x 6^{+/+}$controls $(p<0.0001)$, while in $A P P / P r d x 6^{+/-}$mice it is increased by $31.8 \%(p<0.0001)$. In direct comparison with the $A P P / P r d x 6^{T g}$ line, plaqueassociated astrocytes in APP/Prdx $6^{+/-}$mice show 1.8-fold higher C3 expression $(p<0.0001)$.

Along with the differences in the way how astrocytes engage $A \beta$ plaques we also noticed significant differences in the behavior of plaque-associated microglial cells. In $A P P / \operatorname{Prd} x 6^{T g}$ mice, there is $65 \%$ increase $(p<0.0001)$ in the number of plaque-associated $\mathrm{Iba}^{+}$ microglia cells (Fig. 5a, c), 26\% increase $(p<0.01)$ in the plaque Iba1 index (Iba1 ${ }^{+} \%$ plaque area) (Fig. $5 \mathrm{~d}$ ), 32\% increase $(p<0.05)$ in the microglia barrier robustness index (Iba1/X-34\% co-localization) (Fig. 5e), and 12\% increase $(p=0.16)$ in the CD68 phagosome plaque index $\left(\mathrm{CD} 68^{+} \%\right.$ plaque area) (Fig. 5b. f) compared to APP/ $\operatorname{Prdx} 6^{+/+}$controls. APP/Prdx6 $6^{+/-}$mice display opposite changes in microglia activation metrics. The average number of plaque-associated $\mathrm{Iba}^{+}$microglia cells shows $29 \%$ reduction $(p<0.01)$, plaque Iba1 index $27 \%$ reduction $(p<0.01)$, microglia barrier robustness index 36\% reduction $(p<0.05)$, and CD68 phagosome index $31 \%$ reduction $(p<0.01)$ vs. $A P P / P r d x 6^{+/+}$controls. In direct comparison with $A P P / P r d x 6^{T g}$ line, APP/Prdx6 $6^{+/-}$mice show 2.3-fold lesser number of periplaque $\mathrm{Iba}^{+}$cells $(p<0.0001), \quad 1.7$-fold lower plaque Iba1 index ( $p<0.0001), 2.1$-fold lower microglia barrier robustness index $(p<0.0001)$, and 1.6-fold lower CD68 phagosome index $(p<0.0001)$. There also is a striking effect of $\operatorname{Prdx6}$ gene dose on TREM2 expression by periplaque microglia. $A P P / P r d x 6^{T g}$ mice feature $44 \%$ increase $(p<0.0001)$ in the TREM2 $2^{+}$label of the plaque (TREM2 plaque area) (Fig. 6a, b) and $42 \%$ increase $(p<0.0001)$ in the TREM2/Iba1 ratio (Fig. 6c) reflecting upregulation of TREM2 expression on the individual microglial cell level compared to $A P P / P r d x 6^{+/+}$controls. In contrast, $A P P / P r d x 6^{+/-}$mice show down regulation of TREM2 expression, evidenced by $23 \%$ reduction $(p<0.05)$ in TREM2 plaque area and $31 \%$ reduction $(p<0.001)$ in TREM2/Iba1 ratio compared to APP/Prdx6 $6^{+/+}$controls. In direct comparison with $A P P / P r d x 6^{T g}$ line these metrics are reduced by 1.9 -fold $(p<0.0001)$ and 2.1 -fold $(p<0.0001)$ in APP/Prd $x 6^{+/-}$mice, respectively. Thus, $\operatorname{Prdx6}$ gene dose shows direct relationship with phagocytic activation of periplaque microglia and inverse relationship with the size and compactness of $A \beta$ plaques, what is consistent with function of periplaque microglia recognized for phagocytosing diffuse $A \beta$ in the plaque brim and forming the plaque core. Prdx6 overexpression has a protective effect by enhancing $A \beta$ proteostasis, while Prdx6 haplodeficiency to the contrary confers functional impairment of periplaque microglia in countering $A \beta$ deposits akin to that rendered by TREM2 haplodeficiency or R47H Trem2 mutant [3, 29, 36].

\section{PRDX6 protein is upregulated in plaque-associated astrocytes, but it is undetectable in microglia}

We used multi-antigen labeling and LSCM imaging to interrogate cellular localization of PRDX6 protein in plaqueassociated glial cells. PRDX6 strictly co-localizes to $\mathrm{GFAP}^{+}$ astrocytes and its expression follows $A P P / P r d x 6^{T g}>A P P /$ $\operatorname{Prdx} 6^{+/+}>A P P / P r d x 6^{+/}$gradient across the genotypes (Fig. 7a). Plaque-associated astrocytes feature marked upregulation of PRDX6 expression in comparison to astrocytes in A $\beta$ plaque free, 3-month-old mice (Fig. S5a, b). Redistribution of PRDX6 immunoreactivity from the soma to astrocytic processes is a striking feature of periplaque astrocytic activation. This is pronounced in $A P P / P r d x 6^{T g}$ mice, noticeable in $A P P / P r d x 6^{+/+}$mice, but absent in APP/ $P r d x 6^{+/-}$animals (Fig. S5b). Activated astrocytes in APP/ $\operatorname{Prdx} 6^{T g}$ mice also appear to be more hypertrophied compared to those in $A P P / P r d x 6^{+-}$mice, especially in respect to the processes penetrating plaques (Fig. 4a, Fig. S4a, Fig. $\mathrm{S} 5 \mathrm{~b})$. Apart from astrocytes grouped around $A \beta$ plaques, activated, PRDX6 ${ }^{+}$astrocytes also can be found alongside blood vessels in 10-month-old mice (Fig. S5c). Similarly, expression of PRDX6 by activated, perivascular astrocytes has been described in $\mathrm{AD}$ autopsy material, including vessels which do not exhibit overt cerebral amyloid angiopathy [9]. Akin to plaque-associated astrocytes, perivascular astrocytes also show differences in PRDX6 expression level across the genotypes, which are commensurate with Prdx6 gene dose.

There is no evidence of PRDX6 expression by plaqueassociated microglia. Anti-PRDX6 and anti-Iba1 immunostainings show no co-localization in any of studied genotypes. In fact, the X-34/PRDX6/Iba1 triple labeling reveals two strikingly different, non-overlapping populations of plaque-associated cells: Iba $1^{+}$activated microglia and $\mathrm{PRDX6}^{+}$cells, which judging by their "spider-like morphology" and localization farther apart from the X$34^{+}$fibrillar core, are likely plaque-associated astrocytes (Fig. 7b). In a supplementary experiment, we also examined Prdx6 transcript in affinity-purified microglia cultures where we find its level to be merely $1 \%$ of that in cultured astrocytes, and not increasing following 


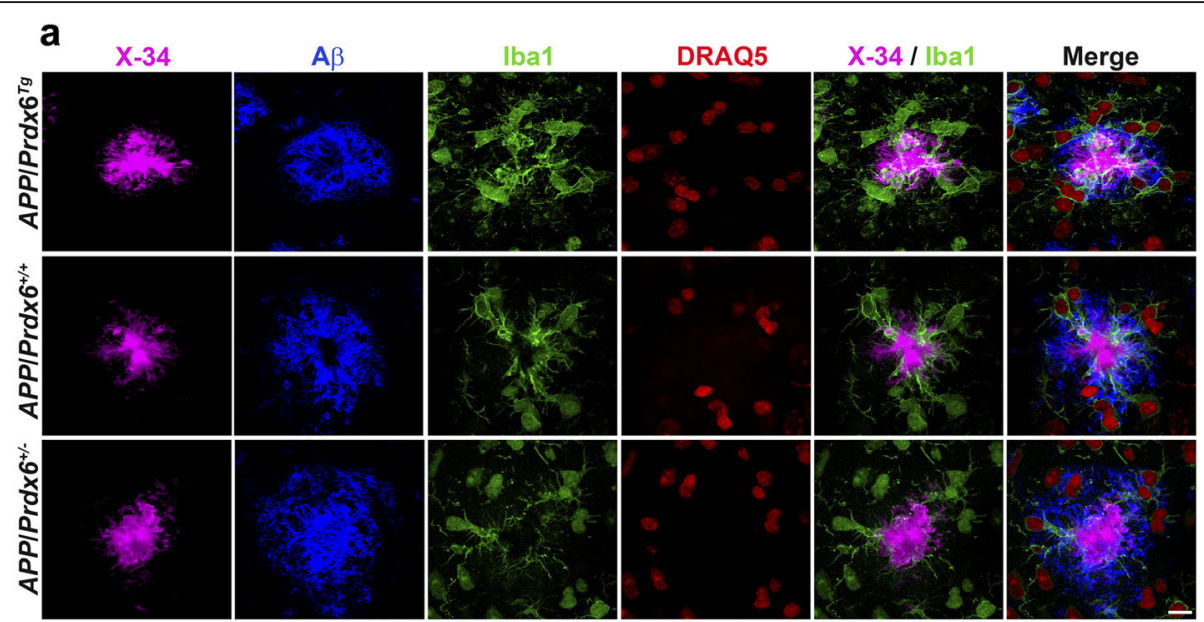

\section{b}

$\mathrm{X}-34$

$A \beta$

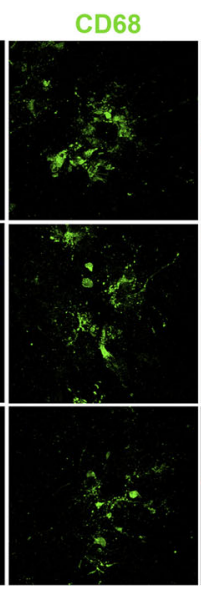

DRAQ5

X-34 / CD68

Merge
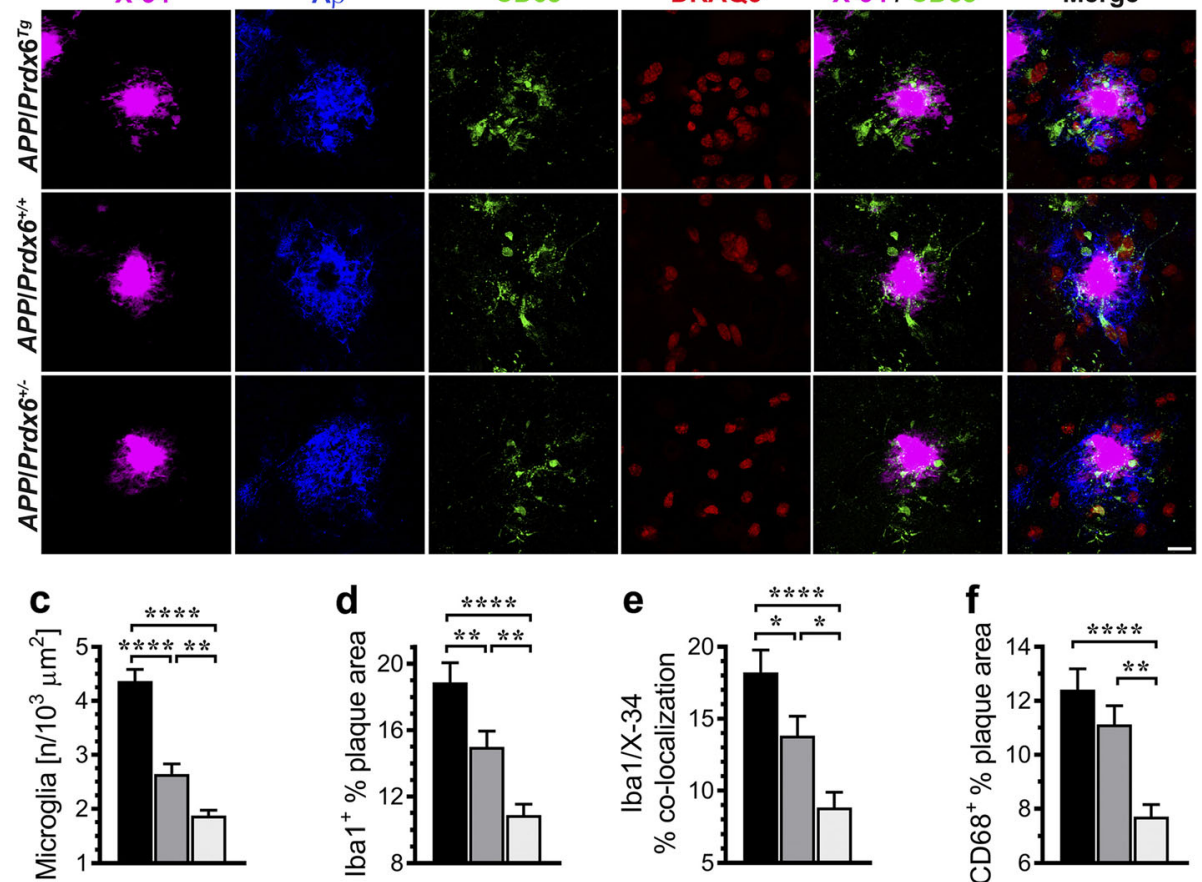

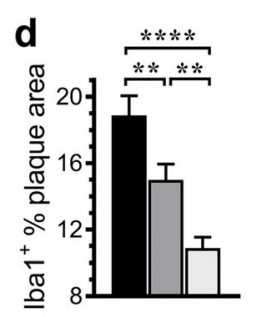

APP/Prd $\times 6^{T g}$

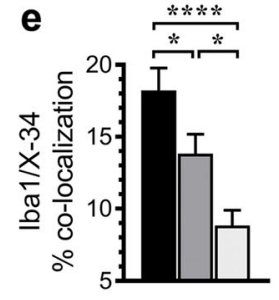

APP/Prd $\times 6^{+/+}$

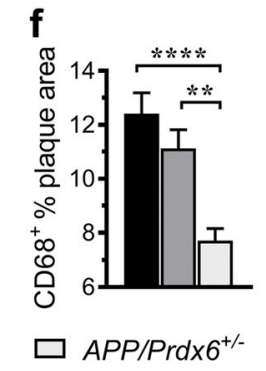

Fig. 5 Phagocytic activation of plaque-associated microglia is enhanced in mice overexpressing Prdx6 and attenuated in Prdx6 haplodeficient mice. Representative LSCM images of mature plaques co-labeled with X-34 (fibrillar core), anti-A 3 (HJ3.4 clone), anti-Iba1, and DRAQ5 (nuclear stain) in $\mathbf{a}$, and with $\mathrm{X}-34$, anti-A 3 , anti-CD68, and DRAQ5 in $\mathbf{b}$ evidencing direct relationship between Prdx6 gene dose and the number of periplaque microglia cells and expression of Iba1 and CD68 microglial activation markers. Shown are morphometric analyses of plaque-associated microglia number $\mathbf{c}$, Iba1 plaque index (Iba1 ${ }^{+} \%$ plaque area) $\mathbf{d}$, microglia barrier robustness (Iba1/X-34\% co-localization) e, and CD68 phagosome plaque index (CD68 $\%$ plaque area) $\mathbf{f}$. Values in $\mathbf{c}$ through $\mathbf{f}$ represent mean ( $+\mathrm{SEM}$ ) from $n=26-35$ randomly selected plaques per staining and per genotype. $p<0.0001$ in $\mathbf{c}$ through $\mathbf{f}$ (ANOVA); ${ }^{*} p<0.05,{ }^{* *} p<0.01$, and ${ }^{* * * *} p<0.0001$ (Holm-Sidak's post-hoc test). Scale bar: $10 \mu \mathrm{m}$ in $\mathbf{a}$ and $\mathbf{b}$

lipopolysaccharide stimulation (Fig. S6). Thus, confirmatory to previous work of us and others $[8,9]$ we endorse that PRDX6 protein is expressed by astrocytes but not by microglia and its level becomes upregulated during astrocytic activation in $\operatorname{Prdx} 6$ gene dose-dependent manner. Our demonstration that manipulation of the expression level of an astrocytic inherent protein produces coextensive effects on periplaque microglia activation implies that astrocytes circuitously guide microglia dependent $A \beta$ plaque processing. 


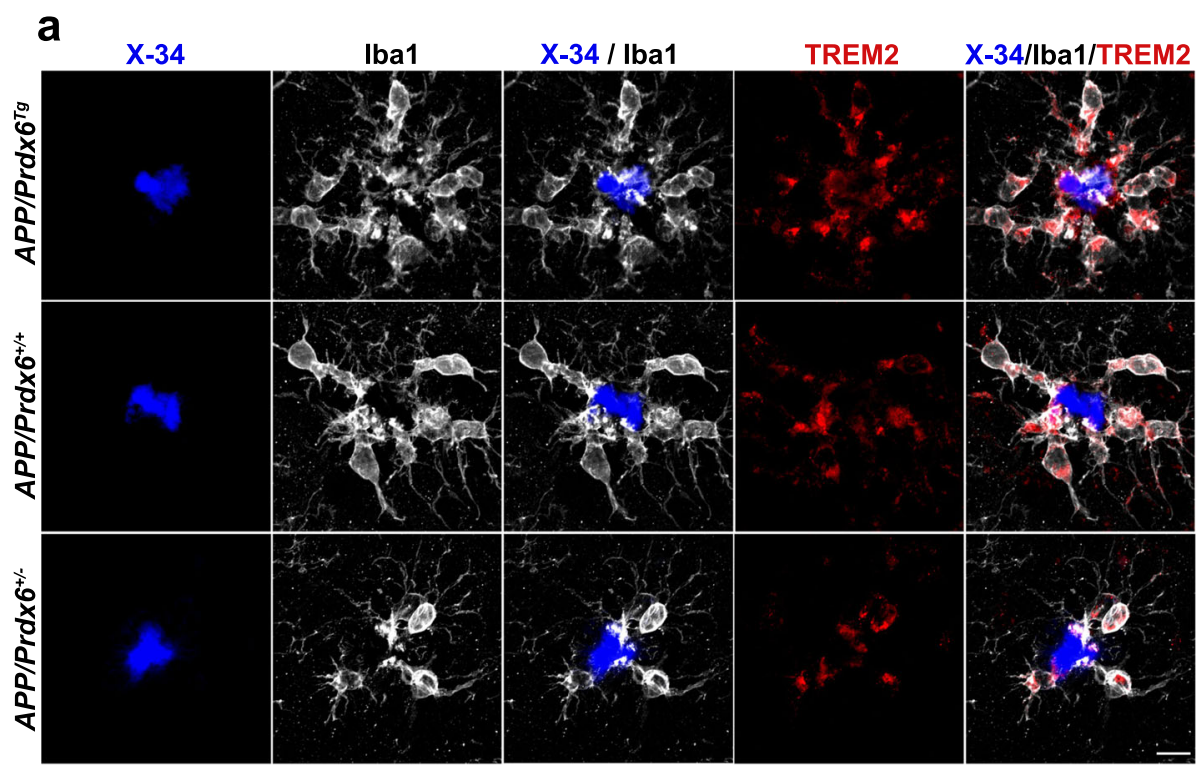

b

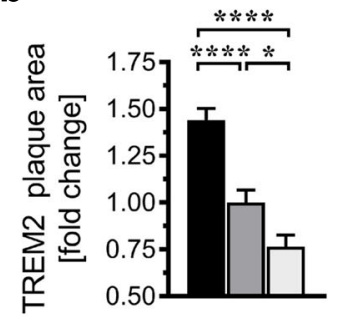

C

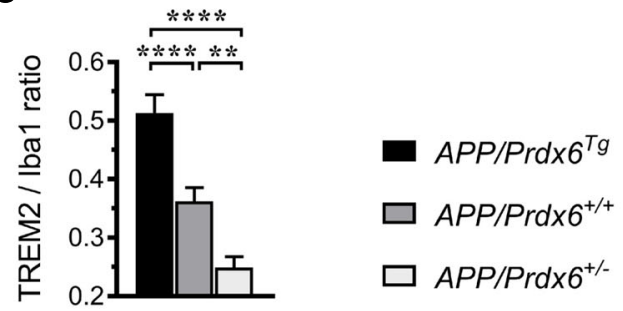

Fig. 6 Expression of TREM2 in plaque-associated microglia shows direct relationship with Prdx6 gene dose. a Representative LSCM images of mature plaques co-labeled with X-34 (fibrillar core), anti-lba1, and anti-TREM2 antibodies from female animals of indicated genotypes evidence increased periplaque expression of TREM2 in APP/Prd $x 6^{\text {Tg }}$ line and conversely reduced expression in APP/Prdx6 ${ }^{+/-}$line compared to APP/Prd $6^{+/+}$ controls. Quantification of TREM2 immunoreactivity within surrounding of the X-34 fibrillar core (TREM2 plaque area) $\mathbf{b}$ and TREM2 to Iba1 ratio in plaque-associated microglia $\mathbf{c}$. Values represent mean (+SEM) from $n=45$ randomly selected plaques per genotype. $p<0.0001$ in $\mathbf{b}$ and $\mathbf{c}$ (ANOVA); ${ }^{*} p<0.05,{ }^{* *} p<0.01$, and ${ }^{* * * *} p<0.0001$ (Holm-Sidak's post-hoc test). Scale bar: $10 \mu \mathrm{m}$ in a

\section{Seeding of nascent $A \beta$ plaque is inhibited by Prdx6} overexpression while promoted by haplodeficiency Early stages of $\mathrm{A} \beta$ deposition remain only partially understood. Increasing concentration of soluble $A \beta$ peptides is believed to drive $A \beta$ self-assembly giving rise to precipitation of the earliest, immunodetectable deposits, which attract glial cells. To explore how variable Prdx6 expression impacts $A \beta$ plaque seeding we quantified numerical density of nascent plaques and their subsets devoid of $\mathrm{GFAP}^{+}$or $\mathrm{Iba1}^{+}$cells on $\mathrm{X}-34 / \mathrm{A} \beta / \mathrm{GFAP}$ or $\mathrm{X}$ $34 / \mathrm{A} \beta / \mathrm{Iba} 1$ triple-labeled sections, respectively. We define nascent plaques as circumscribed, immunopositive $\mathrm{A} \beta$ deposits having no $\mathrm{X}-34^{+}$core or having $\mathrm{X}-34^{+}$core with cross-sectional surface $\leq 40 \mu \mathrm{m}^{2}$ (Fig. $8 \mathrm{a}, \mathrm{b}$ ). This analysis was done in mice aged 6 months, representing an early stage of $\mathrm{A} \beta$ deposition in the $A P P_{\text {swe }} / P S 1_{d E 9} \mathrm{Tg}$ model [13]. In $A P P / \operatorname{Prd} x 6^{T g}$ line the numerical density of all nascent plaques in the brain cortex shows $17 \%$ reduction $(p<0.05)$, while in $\mathrm{APP} / \operatorname{Prd} x 6^{+/-}$mice $22 \%$ increase $(p<0.05)$ compared to APP/Prdx $6^{+/+}$controls (Fig. 8a-d). In comparison with $A P P / P r d x 6^{T g}$ line, 6month-old APP/Prd $x 6^{+/-}$mice have 1.5-fold $(p<0.001)$ higher density of nascent plaques. Numerical densities of plaques devoid of $\mathrm{GFAP}^{+}$or $\mathrm{Iba}^{+}$cells also show significant differences across the genotypes. In APP/ $\operatorname{Prd} x 6^{T g}$ mice numbers of astrocyte and microglia-free plaques are lesser by $33 \%(p<0.01)$ and $43 \%(p<0.001)$ compared to $A P P / P r d x 6^{+/+}$controls, respectively; while in $\mathrm{APP} / \mathrm{Prd} d 6^{+/-}$mice they are increased by $38 \%$ $(p<0.001)$ and $24 \%(p<0.01)$, respectively. In direct comparison between $A P P / P r d x 6^{T g}$ and $\mathrm{APP} / \operatorname{Prd} x 6^{+/-}$ lines, the latter shows 2.1 -fold $(p<0.0001)$ and 2.2-fold $(p<0.0001)$ more of astrocyte and microglia-free plaques, respectively. We also detected significant differences in the phagocytic activity of microglia associated with nascent plaques across the mouse lines. This was determined by quantification of the $\mathrm{CD}^{+} 8^{+}$/ X-34 plaque index in a subset of nascent plaques, which 

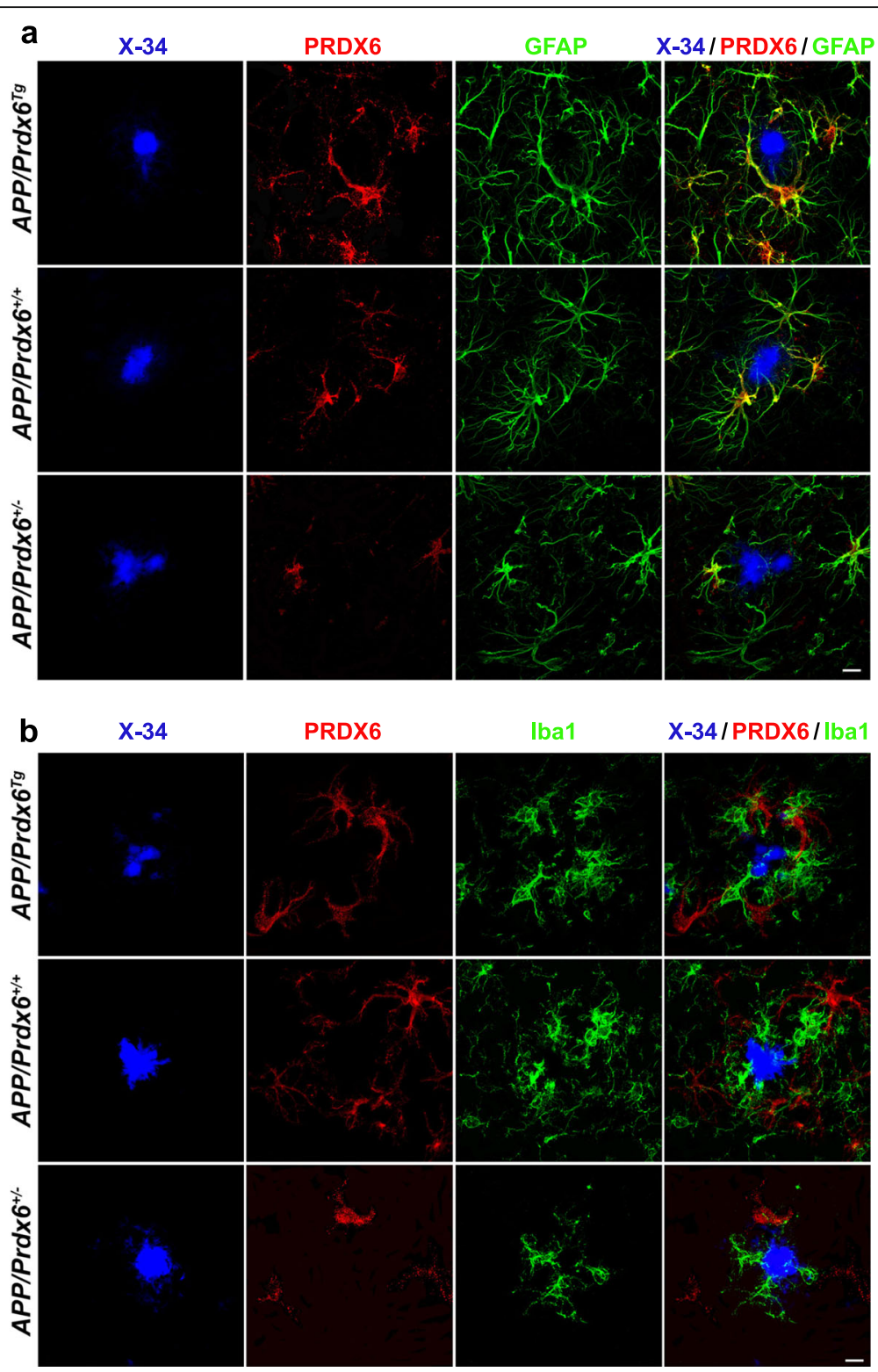

Fig. 7 PRDX6 protein is exclusively expressed by astrocytes and absent in plaque-associated microglia. Representative LSCM images of mature plaques co-labeled with X-34 (fibrillar core), anti-PRDX6, and anti-GFAP antibodies in a, and with X-34, and anti-PRDX6, and anti-Iba1 antibodies in b evidencing colocalization of PRDX6 immunostaining with that of GFAP but not with Iba1. Co-labeling with anti-PRDX6, and anti-lba1 antibodies in $\mathbf{b}$ reveals in fact two distinct cell populations localized further apart and closer to the fibrillar core, respectively. There is apparent $A P P / P r d x 6^{T g}>$ APP/Prd $\times 6^{+/+}>$APP/Prd $6^{+/-}$gradient of PRDX6 immunostaining intensity across the genotypes. PRDX6 immunostaining does not co-localize with the X-34 labeled fibrillar plaque core. Scale bar: $10 \mu \mathrm{m}$ in $\mathbf{a}$ and $\mathbf{b}$

already developed the amyloid core (Fig. S7a, b). APP/ $\operatorname{Prd} x 6^{T g}$ mice exhibit $39.9 \%$ increase in the $\mathrm{CD}^{\mathrm{T}} 8^{+} / \mathrm{X}^{-}$ $34^{+}$plaque index compared to APP/Prdx6 $6^{+/+}$controls $(p<0.0001)$, while in $A P P / P r d x 6^{+/-}$mice the $\mathrm{CD}^{+} 8^{+} / \mathrm{X}-$ $34^{+}$index is reduced by $20.1 \%(p<0.01)$. In direct comparison with $A P P / P r d x 6^{T g}$ line, APP $/ P r d x 6^{+/-}$mice show 1.8-fold lower CD68 ${ }^{+} / \mathrm{X}-34^{+}$index $(p<0.0001)$.

In a complementary experiment, we quantified the load and numerical density of all $\mathrm{Th}-\mathrm{S}^{+}$plaques (nascent
+ mature) in the brain cortex and the hippocampus in mice aged 6 months and this analysis revealed $A P P /$ $\operatorname{Prdx} 6^{T g}<A P P / P r d x 6^{+/+}<A P P / P r d x 6^{+/-}$rank order concerning both metrics with statistically significant differences across the genotypes for either anatomical structure (Fig. S8a-c). Taken together these findings indicate that activity level of astro- and microglia cells effectively impacts early stages of $A \beta$ deposition and that this process is regulated by PRDX6. 

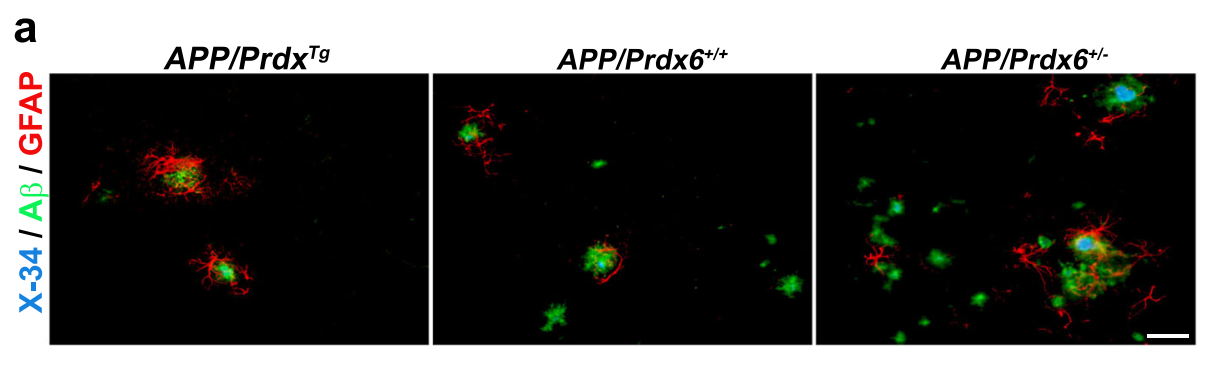

b
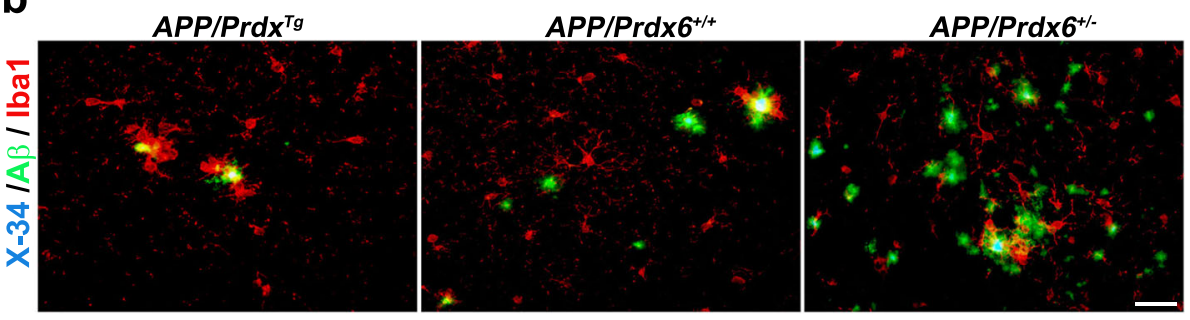

C
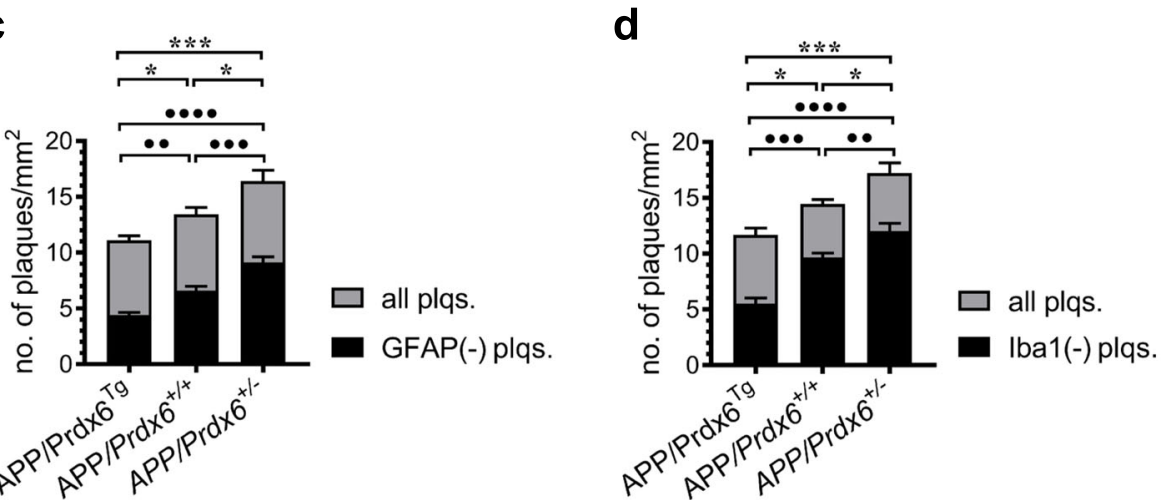

Fig. 8 Prdx6 expression modulates plaque seeding. Shown are representative images of nascent plaques in female mice aged 6 months of indicated genotypes, which were co-labeled with X-34 (fibrillar core), and anti-A 3 (HJ3.4 clone) and anti-GFAP antibodies in a and with X-34, anti$\mathrm{A} \beta$ (HJ3.4 clone), and anti-lba1 antibodies in $\mathbf{b}$ evidencing an inverse relationship between Prdx6 expression level and the numerical density of nascent plaques and the numerical density of nascent plaques devoid of $\mathrm{GFAP}^{+}$and $\mid \mathrm{lba} \mathrm{1}^{+}$cells. Quantitative analysis of nascent plaque numerical density in the brain cortex performed on X-34/AB/GFAP co-labeled sections in $\mathbf{c}$, and on X-34/AB/lba1 co-labeled sections in $\mathbf{d}$. In this analysis nascent plaques were arbitrary defined as having no X-34 $4^{+}$core or having $\mathrm{X}-34^{+}$core $<40 \mu \mathrm{m}^{2}$. Black bars represent number of plaques devoid of $\mathrm{GFAP}^{+}$or $\mathrm{Iba}^{+}$cells $/ \mathrm{mm}^{2}$ and are superimposed on grey bars representing the total number of plaques $/ \mathrm{mm}^{2}$ for a given genotype. Values in $\mathbf{c}$ and $\mathbf{d}$ represent mean (+SEM) from $n=6$ female mice per genotype. $p<0.0001$ in $\mathbf{c}$ and $\mathbf{d}$ (ANOVA); $\boldsymbol{\bullet} p<0.01, \boldsymbol{\bullet \bullet}^{\circ} p<0.001$, and $\cdots p<0.0001$ denote significance for the density of GFAP and Iba1 devoid plaques across genotypes; ${ }^{*} p<0.05$, and ${ }^{* * *} p<0.001$, denote significance for the density of all plaques (Holm-Sidak's post-hoc test). Scale bar: $20 \mu \mathrm{m}$ in $\mathbf{a}$ and $\mathbf{b}$

Plaque-associated axonal dystrophy varies inversely with Prdx6 gene dose

Numerical density of neuritic plaques was quantified in female mice aged 10 months on section impregnated with Gallyas silver stain $[25,26,28]$. In $A P P / P r d x 6^{T g}$ mice, neuritic plaque density in the brain cortex and the hippocampus is reduced by $38 \%(p<0.0001)$ and $39 \%$ $(p<0.01)$ compared to APP/Prdx $6^{+/+}$controls, respectively; while in $\mathrm{APP} / \mathrm{Prd} x 6^{+/-}$mice conversely it shows $31 \%(p<0.0001)$ and $29 \%(p<0.05)$ increase, respectively (Fig. 9a, b). In comparison with $A P P / P r d x 6^{T g}$ line, the numerical density of neuritic plaques in APP/ $\operatorname{Prd} x 6^{+/-}$mice is 2.1 -fold higher in either the brain cortex or the hippocampus $(p<0.0001)$. There also are noticeable differences in the morphology of neuritic plaques across the genotypes. These concern the number of argentophilic spheroids and the distance they spread out from the plaque center following the $A P P / P r d x 6^{T g}<$ $A P P / P r d x 6^{+/+}<A P P / P r d x 6^{+/-}$rank order (Fig. 9a, c). Argentophilic spheroids represent focal swelling of axons, which degenerate passing through diffuse $A \beta$ amassed around the plaque fibrillar core. They also are known to accumulate endosomal vesicles and neurofilaments [37], thus, we used double anti-A $\beta /$ anti-neurofilament (NF) immunolabeling protocol to further characterize the impact of $\operatorname{Prdx} 6$ gene dose on axonal 


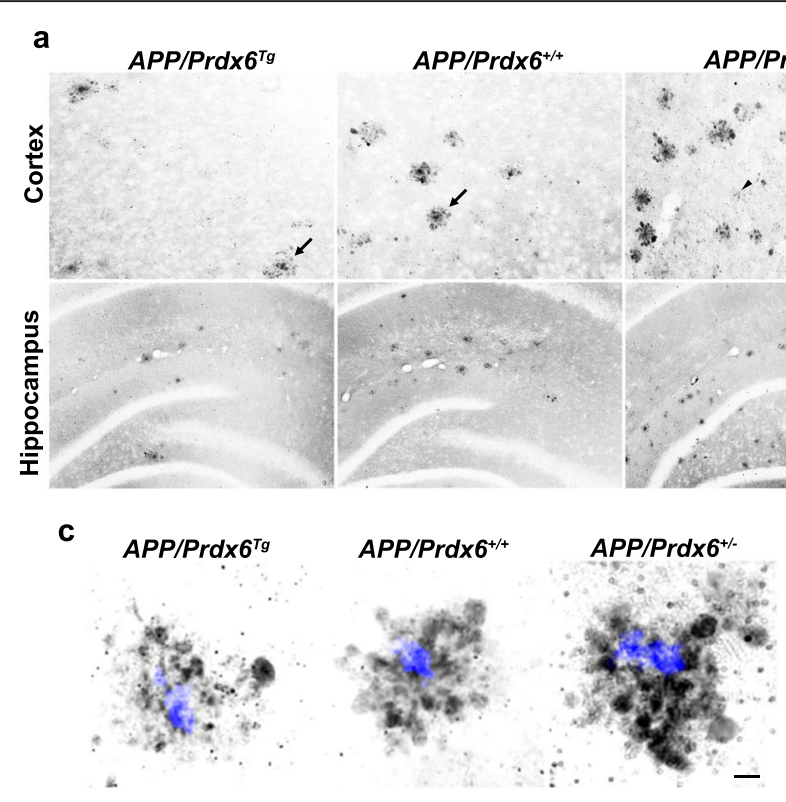

d
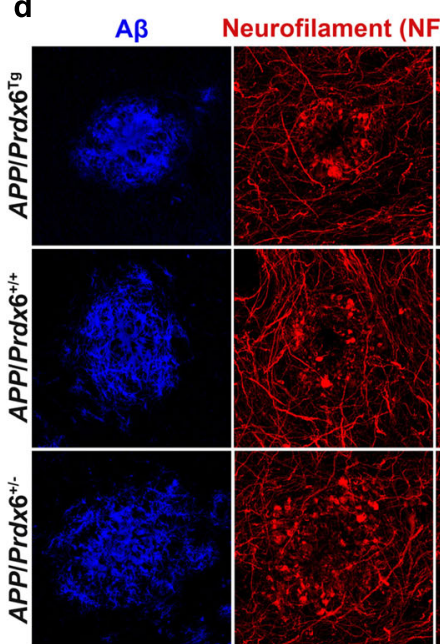

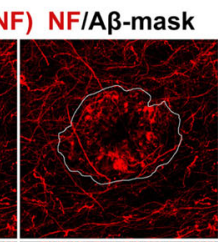

$A \beta / N F$
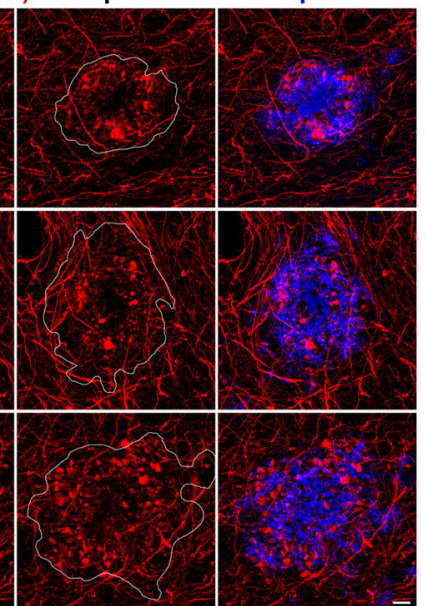

e

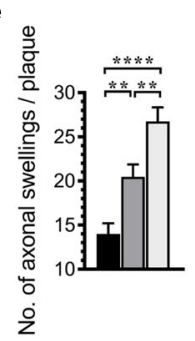

f

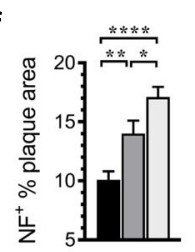

Fig. 9 Neuritic degeneration is attenuated in APP SWE/PS1 $1_{\text {EEg }}$ mice overexpressing Prdx6 and exacerbated in Prdx6 haplodeficient mice. a Shown are representative microphotographs of coronal cross-sections through the somatosensory cortex (upper panel) and the dorsal hippocampus (lower panel) from 10-month-old female mice of indicated genotypes, which were stained with Gallyas silver stain. Both the numerical density of neuritic plaques and the number and size of spheroid bodies forming the plaques increase in the rank order of APP/Prd $\sigma^{\text {Tg }}<A P P / P r d 6^{+/+}<A P P /$ $\mathrm{PrdG}^{+/-}$. Arrows indicate mature plaques while arrowheads indicate early stage of neuritic degeneration associated with emerging plaques, which are abundant in the APP/Prd6 ${ }^{-1-}$ mice. $\mathbf{b}$ Quantitative analysis of numerical density of Gallyas ${ }^{+}$neuritic plaques in the brain cortex and in the hippocampus depicted as mean value (+SEM) from $n=6$ female mice per genotype. c Shown are high magnification microphotographs of neuritic plaques produced by superimposing bright field picture of silver impregnated spheroids on fluorescent image of X-34 labeled fibrillar plaque core highlighting the differences in plaque composition across the genotypes, which include both the number and the distance spheroid spread away from the fibrillar core. $\mathbf{d}$ Representative LCMS images of plaques co-labeled with antibodies against the N-terminus of A $\beta$ peptide $\left(A \beta_{1-16}\right)$ and neurofilaments (NF) from female mice of indicated genotypes demonstrating distorted trajectories of axons passing in the vicinity of the plaques and presence of axonal swellings (spheroids) in the area occupied by anti-A $\beta$ immunolabeling (white encirclement indicated by $A \beta$ plaque mask). Quantification of the number of $\mathrm{NF}^{+}$axonal swellings per $\mathrm{A} \beta$ plaque in e and $\mathrm{NF}^{+}$plaque index ( $\left(\mathrm{NF}^{+} \%\right.$ plaque area) in $\mathbf{f}$. Values represent mean (+SEM) from $n=40$ randomly selected plaques per genotype. $p<0.001$ for the hippocampus in $\mathbf{b}$, and $p<0.0001$ for the brain cortex in $\mathbf{b}$, e, and $\mathbf{f}$ (ANOVA); ${ }^{*} p<0.05,{ }^{* *} p<0.01$, and ${ }^{* * * *} p<0.0001$ (Holm-Sidak's post-hoc test). Scale bars: $50 \mu \mathrm{m}-$ the cortex and $200 \mu \mathrm{m}$ the hippocampus in $\mathbf{a}$, and $10 \mu \mathrm{m}$ in $\mathbf{c}$ and $\mathbf{d}$

dystrophy (Fig. 9d). APP/Prdx $6^{T g}$ mice show reduction in the average number of NF-positive swelling per plaque by $32 \%(p<0.01)$ and in the NF plaque index
$\left(\mathrm{NF}^{+} \%\right.$ plaque area $)$ by $28 \%(p<0.01)$ compared to $A P P / P r d x 6^{+/+}$controls, while in APP $/ P r d x 6^{+/-}$mice there is $31 \%(p<0.01)$ and $28 \%(p<0.01)$ increase in 
these metrics, respectively (Fig. 9e, f). In direct comparison with $A P P / P r d x 6^{T g}$ line, $\mathrm{APP} / \mathrm{Pr} d x 6^{+/-}$mice show 1.9-fold more of NF-positive swellings per plaque $(p<0.0001)$ and 1.7-fold higher NF plaque index $(p<0.0001)$.

\section{Discussion}

Unlike microglia, function of astrocytes in $A \beta$ proteostasis has received limited attention and remains of rudimentary understanding [38]. Peri-plaque astrocytic activation has been classically viewed as a passive response to neuritic degeneration through formation of a glial scar [39]. Here, we provide novel evidence that astrocytes play an active role in countering $A \beta$ deposition, and identify PRDX6 protein as a key element of this process. PRDX6 is expressed by astrocytes but no other type of CNS glial cells $[8,9]$. As a prerequisite for this study, we determined that two-fold change in $\operatorname{Prdx} 6$ expression level does not affect astrocyte-resting state or alter soluble $A \beta$ levels in AD Tg mice prior to appearance of $\mathrm{A} \beta$ plaques. Altered $\operatorname{Prdx6}$ expression also does not influence mounting of $A \beta$-associated astrogliosis, as the load of $\mathrm{GFAP}^{+}$astrocytes remains proportional to that of fibrillar $\mathrm{A} \beta$ plaques. However, we find a striking, direct dependence between $\operatorname{Prdx} 6$ gene dose and propensity of astrocytes to engage and penetrate $A \beta$ plaques. We also show that $\operatorname{Prdx} 6$ gene overexpression is associated with reduced $A \beta$ plaque load through suppression of nascent plaque seeding and remodeling of mature plaque by phagocytically activated microglia, while Prdx6 haplodeficiency conversely effects increased A $\beta$ load in association with reduced periplaque microglia activation (Fig. 10 a-d). Demonstration that altering expression of an astrocytic inherent protein produces coextensive effect on periplaque microglia implies that astrocytes circuitously guide microglia dependent $A \beta$ plaque processing.

PRDX6 is a cytoplasmic, enzymatic protein with independent Gpx and PLA 2 activities [40]. Gpx activity is endowed by ${ }^{\mathrm{Cys}} 47$, while the PLA 2 activity by the triad of ${ }^{\mathrm{Ser}_{3}}$, ${ }^{\mathrm{His}} 26$, and ${ }^{\mathrm{Asp}} 140$ brought into a single catalytic site by the tertiary PRDX6 folding [41]. PRDX6 is abundant in lung epithelium, endothelium, hepatocytes, and peripheral macrophages [5], where it is involved in antioxidant defense (with $\mathrm{H}_{2} \mathrm{O}_{2}$, short chain hydroperoxides, and phospholipid hydroperoxides as reduction substrates), phospholipid turnover, and cellular signaling [5]. In particular, PRDX6 is recognized for its ability to restitute peroxidized cell membrane lipids by their reduction through Gpx activity or excision through $\mathrm{PLA}_{2}$ action with subsequent replacement by $\mathrm{PLA}_{2}$-conjugated lysophosphatidylcholine acyl transferase activity. This particular functionality of PRDX6 is essential for the integrity of lung epithelium endowing resistance to constant oxidative damage $[5,6]$. In $\mathrm{AD}, \mathrm{A} \beta$ plaques constitute a source of locally confined yet enduring oxidative stress, which contributes importantly to disease pathogenesis by rendering protein misfolding, impairing ability of microglia to phagocytose $A \beta$ while promoting their pro-inflammatory phenotype, and effecting neuritic degeneration [42]. Astrocytes, which penetrate $A \beta$ plaques need to withstand consequences of chronic oxidative stress. In this study we showed that penetrance of $A \beta$ plaques by astrocytes is associated with upregulation of PRDX6 protein expression along with redistribution of PRDX6 from the cell body to astrocytic processes. Similar reactive behavior of PRDX6 is known from extra-CNS cell lineages where oxidative stress upregulates PRDX6 level and promotes its translocation from the cytosol to the cell membrane allowing access to peroxidized lipids as the metabolic substrate [43]. In our previous work, we experimentally proved that PRDX6 renders astrocytes resistant to oxidative damage [8]. Astrocytes cultured from $\operatorname{Prdx6}$ overexpressing mice exhibit increased resistance to in vitro oxidative insult while astrocytes cultured from $\operatorname{Prdx6^{-/-}}$ mice, conversely show significantly reduced viability. Thus, greater penetrance of $\mathrm{A} \beta$ plaques by astrocytes in $A P P / P r d x 6^{T g}$ mice and reduced penetrance in $A P P / P r d x 6^{+-}$mice reflect increased and decreased resistance of astrocytes to plaque-associated oxidative stress, respectively. Interestingly, we also observed that PRDX6 overexpressing astrocytes, which engage $A \beta$ plaques have significantly reduced expression of $\mathrm{C} 3$, which is a marker of astrocytic neurotoxic phenotype, also known as A1 [33-35]. Conversely, in Prdx6 haplodeficient mice, which cannot mount proper PRDX6 expression, astrocytes not only poorly penetrate $A \beta$ plaques but they also show upregulation of $\mathrm{C} 3$ expression. These results imply that chronic oxidative stress may contribute importantly to astrocytes assuming neurotoxic phenotypes, and that PRDX6 besides increasing endurance to oxidative insult helps in maintaining astrocytic homeostasis.

PRDX6 also is widely recognized for cellular signaling owing to its PLA $_{2}$ activity, and this functionality is triggered by various cellular stressors requiring oxidative, inflammatory, and mechanical stress response [5, 7]. PRDX6/PLA 2 activity can engage several signaling pathways including down-stream activation of NADPH oxidase 2 (NOX2), which is a member of the NOX/DuOX enzyme family generating $\mathrm{O}_{2}{ }^{*-}$ or $\mathrm{H}_{2} \mathrm{O}_{2}[44,45]$. Although rapid and uncontrollable release of $\mathrm{O}_{2}{ }^{--}$or $\mathrm{H}_{2} \mathrm{O}_{2}$ is a culprit in tissue injury during acute oxidative stress, low levels of either intracellular or extracellular $\mathrm{O}_{2}{ }^{-*}$ or $\mathrm{H}_{2} \mathrm{O}_{2}$ messengers are deemed essential for many homeostatic processes, involving intracellular signaling, microbial defense and guiding immune cell chemotaxis into sites of inflammation [46-50]. A well-established 


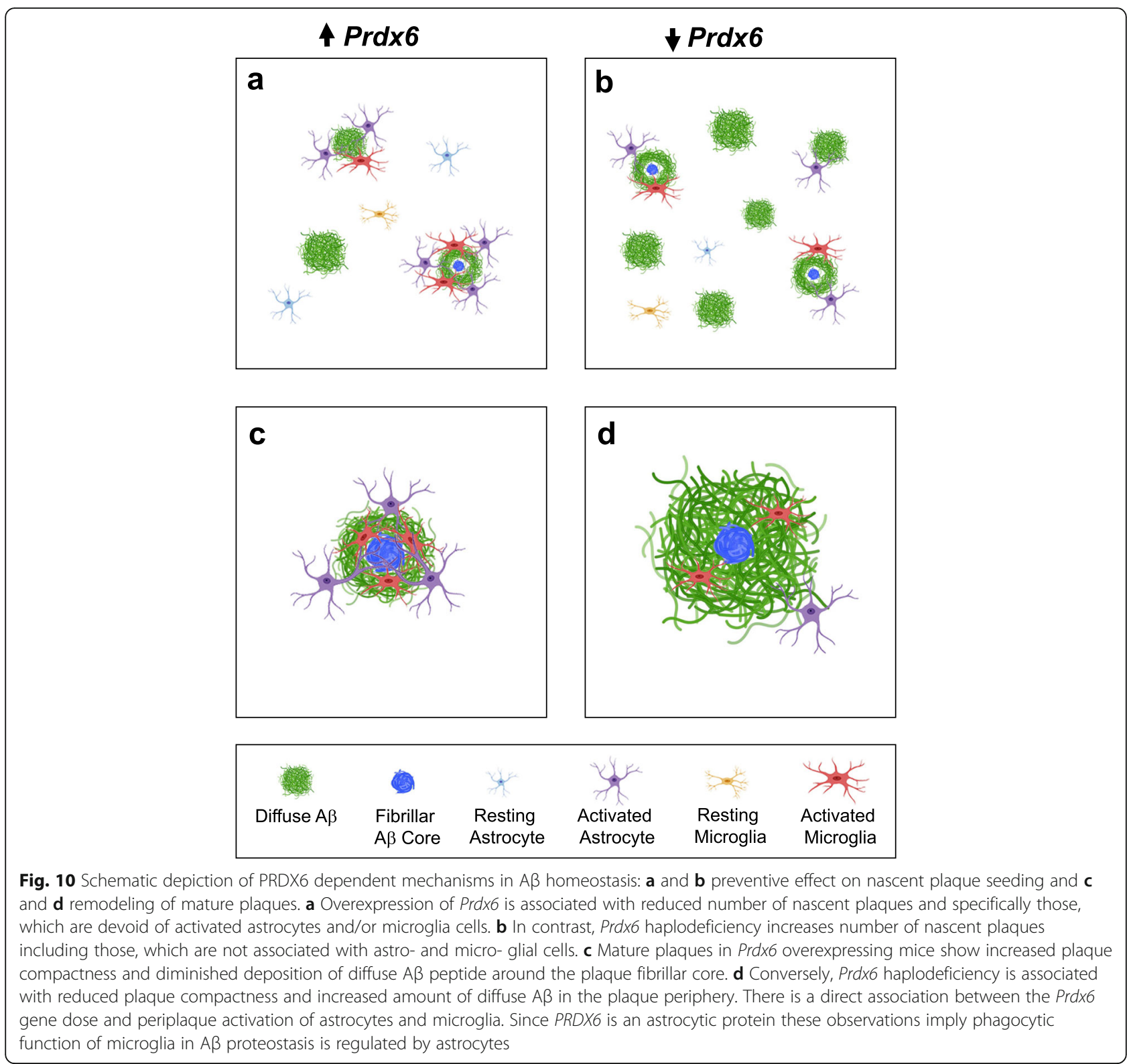

example of such, is NOX2-dependent activation of tolllike receptor (TLR) pathway promoting antibacterial autophagy [51]. Other examples of $\mathrm{PLA}_{2}$-dependent signaling include arachidonic acid pathway [52] and nuclear factor kappa B (NF-kB) pathway [53], which are up and downregulated by PRDX6 level, respectively. In summary, we hypothesize that the beneficence of PRDX6 overexpression against $A \beta$ pathology is owed both to its anti-oxidative function, which increases oxidative stress endurance and allows for a more robust penetration of $\mathrm{A} \beta$ deposits by astrocytes and for the signaling function of $\mathrm{PLA}_{2}$ by which astrocytes circuitously can modulate the activity of plaque-associated microglia. It also is important to conceptualize, that with their somas located outside $A \beta$ plaques and a substantial number of their processes spreading outward into the brain parenchyma, activated astrocytes are well-poised to extent signaling message far distant from the perimeter of $A \beta$ deposits they engage. As the role of astrocytic PRDX6/PLA 2 in cellular signaling remains unexplored, ours is the first observation to suggest it may be involved in astro/microglia crosstalk. Certainly, aforementioned PRDX6/PLA ${ }_{2}$ related signaling pathways like TLR and NF- $k B$ are regarded important to microglia function [54-56]. Thus, in the future studies it will be imperative to precisely determine, which of these pathways underlie astrocyte/ microglia cooperative effort to counter $A \beta$ deposition.

Incipient stages of $A \beta$ deposition remain underexplored. It is unclear how nascent $A \beta$ plaques become recognized by glial cells and what sequence of events 
leads to periplaque glia activation. In the CNS, astrocytes numerically surpass microglia and form a dense surveying network readily responding to changes affecting milieu of the nervous tissue. Examining early stage of $A \beta$ deposition in 6-month-old mice, we found that the numerical density of nascent plaques and the subset of these plaques devoid of astrocytes and microglia companionship vary inversely with the Prdx6 gene dose. We also found that phagocytic activity of microglia associated with nascent plaques remains directly proportional to the Prdx6 expression. These observations merit two conclusions. Firstly, that PRDX6 is involved in engagement of nascent plaques by co-operative action of astrocytes and microglia and secondly, that a portion of newly seeded plaques is cleared by activated microglia. Though the second notion may appear speculative, it is supported by the fact that the level of APP transcript and the level of soluble $A \beta$ prior to the onset of $A \beta$ deposition are similar across all three analyzed transgenic mouse lines rendering them similarly capable of plaque seeding. Our histopathological analysis also endorses recently published spatio-temporal transcriptomic studies in $\mathrm{AD} \mathrm{Tg}$ mice, which indicate transcriptome alterations in astrocytes and microglia occur in parallel and coincide with emergence of early $A \beta$ deposits $[57,58]$. Thus, both studies emphasize an importance of astro/microglia cooperative effort in maintaining $A \beta$ homeostasis.

Likewise, mature plaques we examined in mice aged 10 months reveal influence of $\operatorname{Prdx} 6$ gene dosage on their morphology and degree of periplaque microglia activity. A $\beta$ plaques in $\operatorname{Prdx} 6$ overexpressing mice feature reduced amount of diffuse $A \beta$ in the plaque brim, increased plaque compactness, and increased number and phagocytic activity of plaque-associated microglia. Such morphological changes reflect established function of microglia, known to phagocytose $A \beta$ peptide in the plaque brim what limits plaque diffusion and facilitates compacting $\mathrm{A} \beta$ within the fibrillar core [36]. In $\operatorname{Prdx6}$ hemizygous mice $A \beta$ plaques exhibit opposite features including increased amount of loose, non-fibrillar $A \beta$ in the plaque brim and reduced plaque/core ratio indicative of reduced plaque compactness. Diminished number of periplaque microglial cells and microglia phagocytosis markers remain consistent with this more diffuse plaque morphology, resembling plaques in AD mice with Trem 2 hemizygocity or those harboring Trem $2 \mathrm{R} 47 \mathrm{H}$ mutant, both of which confer loss of TREM2 function and impair $A \beta$ proteostatic function of microglia [29]. In fact, in our study peri-plaque microglia in $\operatorname{Prdx} 6$ hemizygous mice feature reduced TREM2 expression, while those in $\operatorname{Prdx} 6$ overexpressing mice show TREM2 upregulation. TREM2 and the TREM $2 / \mathrm{mTOR}$ signaling pathway are recognized for their critical role in promoting phagocytic activity of microglia and other cells of myeloid linage [4].
However, how TREM2 expression is triggered during microglia activation and how it is sustained effecting microglia phagocytic phenotype remains unclear [59]. TREM2 activity is suppressed by activation of the NF- $\mathrm{kB}$ [59] pathway, which also is inversely regulated by PRDX6 expression level [53]. TREM2 also is stimulated by a set of specific ligands, including apoE $[4,59]$, which plaque content directly correlates with PRDX6 expression. Hence, through cellular signaling and increased apoE plaque content PRDX6 can exert two-prong effect on promoting TREM2 activity in periplaque microglia.

Axons passing through diffuse $A \beta$ in the plaque periphery undergo degeneration forming spherical bodies $[36,37]$ and we found neuritic degeneration to be another essential feature directly associated with $\operatorname{Prdx} 6$ gene dose. There is reduced numerical density of neuritic plaques in $\operatorname{Prdx} 6$ overexpressing mice and conversely their density is increased in Prdx6 hemizygous animals. While, these differences can be explained by variable effect of Prdx6 expression on plaque seeding and resulting discrepancies in plaque density, we also found dissimilarities in the amount of degenerating axons within individual plaques. These differences likely reflect differential effect of $\operatorname{Prdx6}$ gene dosage on phagocytic activity of periplaque microglia and resulting degree of plaque diffusion [36]. It is also possible that anti-oxidant activity of PRDX6 itself contributes to attenuating neuritic degeneration as this process is driven by oxidative stress [42]. However, PRDX6 is compartmentalized to the cytoplasm and its anti-oxidant activity takes place primarily intracellularly rather than it is known to exert significant extracellular effect [5].

While this study utilizes models of chronic neurodegeneration and its conclusions imply beneficence of PRDX6 overexpression in A $\beta$ pathology, opposing findings were described using acute/subacute models of neurodegeneration. Yun et al. showed that intraventricular infusion of oligomeric $A \beta_{42}$ in mice transgenically overexpressing $\operatorname{Prdx} 6$ paradoxically exacerbates oxidative stress and metrics of neurodegeneration compared to wild type mice [60]. Similarly, the same group showed that administration of MPTP to Prdx6 Tg mice exacerbate loss of dopaminergic neurons in the substantia nigra compared to wild type animals [61]. Results of both studies suggest that overexpression of PRDX6 may potentiate outcome of an oxidative insult in the CNS. However, studies concerning PRDX6 function in the lungs may provide insight into understanding these seemingly opposing outcomes. There is extensive literature to indicate opposing behavior of pulmonary PRDX6 during chronic vs. fulminant oxidative insult (reviewed in [5]). While PRDX6 is recognized for its essential role in maintaining the integrity of cellular membranes in the pulmonary epithelium, which is exposed to chronical 
low-grade oxidative stress, in acute lung injury, (e.g. in the course of sepsis), over activation of $\mathrm{PLA}_{2} / \mathrm{NOX} 2$ signaling pathway may lead to uncontrolled generation of $\mathrm{O}^{*-}$ or $\mathrm{H}_{2} \mathrm{O}_{2}$ and paradoxical exacerbation of lung injury. Based on the original observations made by Yun and colleagues, brain PRDX6 also may be capable of paradoxical amplification of oxidative stress related injury. However, since $A \beta$ deposition is an inherently protracted phenomenon, associated with chronic, low-level oxidative stress, we elected to test the role of PRDX6 in this process by developing and examining novel APP/ PS1 Tg mice varying in Prdx6 gene expression. In contrast to the model utilizing intraventricular infusion of preformed $A \beta_{1-42}$ oligomers, we demonstrated beneficence of PRDX6 overexpression in A $\beta$ deposition and associated neurodegeneration, which we also confirmed by showing opposing outcomes when PRDX6 expression was reduced.

Unlike other cell types, astrocytes remain strikingly under-investigated in AD-related research [38]. There are few reports tying astrocyte dysfunction to propagation of $A \beta$ pathology. Deletion of Gfap and vimentin genes encoding intermediate filaments of astrocytic cytoskeleton was shown to impair migration of astrocytes toward $A \beta$ plaques, which resulted in accelerated plaque pathogenesis and enhanced neuritic degeneration in $\mathrm{AD}$ $\mathrm{Tg}$ mice [62]. Also, astrocytic rarefaction of $\mathrm{A} \beta$ plaques was identified as one of the neuropathological hallmarks in rapidly progressing $\mathrm{AD}$, which is a rare but aggressive $A D$ variant. Proteomic analysis in rapidly progressing AD identified PRDX6 as one of top proteins, whose peri-plaque expression is significantly reduced compared to sporadic disease [63]. In the backdrop of these observations, our study provides original insights into a role of astrocytes in $A \beta$ proteostasis by proposing that astrocytes rather than being passive by-standers actively recognize $A \beta$ deposits and circuitously modulate microglia phagocytic activity to counter $A \beta$ accumulation. Plaques that escape initial seeding control and continue to grow remain penetrated by astrocytes, which resistance to oxidative stress is mediated by PRDX6 antioxidant capacity. Astrocytes also propagate phagocytic activity of microglia, which limits plaque diffusion and curtails neuritic degeneration and this effect may be endowed by $\mathrm{PLA}_{2}$ signaling functionality of PRDX6. Thus, emerging evidence recognizes astrocytes as important players in $\mathrm{A} \beta$ proteostasis, and suggests that upregulation of PRDX6 expression can be of therapeutic benefit in AD.

\section{Conclusions}

Our work identifies PRDX6 as an important factor selectively regulating periplaque activation of astrocytes and playing a critical role in astro/microglia cross talk in maintaining $A \beta$ proteostasis.

\section{Supplementary information}

Supplementary information accompanies this paper at https://doi.org/10. 1186/s13024-020-00401-8.

\begin{abstract}
Additional file 1: Figure S1. Comparative analysis of $A B$ plaque load in female and male littermates shows significant opposing effects of $\operatorname{Prdx6}$ overexpression and haplodeficiency in both sexes. Figure $\mathbf{S 2}$ Segmentation analysis of LSCM images of A $\beta$ plaques. Figure $\mathbf{S 3}$ Overexpression of Prdx6 is associated with increased accumulation of apoE within Aßplaques, while Prdx6 haplodeficiency conversely reduces apoE plaque content. Figure S4. Expression of complement component 3 (C3) by plaque associated astrocytes varies inversely with $\operatorname{Prdx6}$ gene dose. Figure S5. Development of $A \beta$ pathology is associated with upregulation of PRDX6 protein expression in astrocytes. Figure $\mathbf{S 6 .}$ Analysis of Prdx6 RNA level in microglia cells. Figure S7. Phagocytic activity of microglia cells surrounding nascent plaques varies directly with Prdx6 gene dose. Figure S8. Prdx6 gene dose affects early stage of A $\beta$ deposition. Supplementary methods. Table S1. Two-way ANOVA analysis of fibrillar and $A \beta$ plaque load in the brain cortex and in the hippocampus in 10-month-old female and male littermates from APP/Prd $6^{T g}, A P P /$ $\operatorname{Prd} \times 6^{+/+}$, and APP/Prd $\times 6^{+/-}$transgenic mouse lines.
\end{abstract}

\section{Abbreviations}

A 3 : $\beta$-amyloid; AD: Alzheimer's disease; APP: Amyloid precursor protein; CD68: Cluster of differentiation 68; CNS: Central nervous system; GFAP: Glial fibrillary acidic protein; Gpx: Glutathione peroxidase; Iba1: Ionized calcium binding adaptor molecule; PLA 2 : Phospholipase A2; Prdx6: Peroxiredoxin 6 gene; PRDX6: Peroxiredoxin 6 protein; PS1: Presenilin 1; Th-S: Thioflavin-S; TREM2: Triggering Receptor Expressed in Myeloid cells 2

\section{Acknowledgements}

We would like to thank Dr. D. M. Holtzman from Washington University School of Medicine (St. Louis, MO) for providing HJ2, HJ3.4, and HJ7.4 antiA $\beta$ monoclonal antibodies and HJ6.3 monoclonal antibody against murine apoE and Dr. Gary E. Landreth from Indiana University School of Medicine (Indianapolis, IN) for advising us on TREM2 immunohistochemistry.

\section{Authors' contributions}

J.E.P. and M.J.S. conceived of the project and designed the experiments. J.E.P., J.R.D., M.M.A., A.M.L., and L.A.F. conducted the research. J.E.P., J.R.D., M.M.A., A.M.L., and M.J.S. analyzed the data. M.J.S. wrote the manuscript. All authors have read and approved the final version of the manuscript.

\section{Authors' information}

N/A

\section{Funding}

This work was supported by grants from the National Institute on Aging R01 AG031221 (M.J.S.), R01 AG053990 (M.J.S.), and R01 AG067478 (M.J.S.).

\section{Availability of data and materials}

Raw images and datasets that support the findings of this study are available from the corresponding author upon reasonable request.

\section{Ethics approval and consent to participate}

All mouse care and experimental procedures were approved by Institutional Animal Care and Use Committees of the New York University School of Medicine.

\section{Consent for publication}

N/A

\section{Competing interests}

The authors declare no competing interests.

\section{Author details}

${ }^{1}$ Department of Neurology, New York University Grossman School of Medicine, 550 First Avenue, Science Building, Room 10-07, New York, NY 10016, USA. ${ }^{2}$ Department of Biochemistry and Molecular Pharmacology, New York University Grossman School of Medicine, New York, NY 10016, USA. 
${ }^{3}$ Department of Psychiatry, New York University Grossman School of Medicine, New York, NY 10016, USA.

\section{Received: 20 February 2020 Accepted: 24 August 2020} Published online: 09 September 2020

\section{References}

1. Hanseeuw BJ, Betensky RA, Jacobs HIL, Schultz AP, Sepulcre J, Becker JA Cosio DMO, Farrell M, Quiroz YT, Mormino EC, et al. Association of Amyloid and tau with Cognition in preclinical Alzheimer disease: a longitudinal study. JAMA Neurol. 2019.

2. Shi Y, Holtzman DM. Interplay between innate immunity and Alzheimer disease: APOE and TREM2 in the spotlight. Nat Rev Immunol. 2018;18:759-72.

3. Yuan P, Condello C, Keene CD, Wang Y, Bird TD, Paul SM, Luo W, Colonna M, Baddeley D, Grutzendler J. TREM2 Haplodeficiency in mice and humans impairs the microglia barrier function leading to decreased amyloid compaction and severe axonal dystrophy. Neuron. 2016;90:724-39.

4. Ulland TK, Colonna M. TREM2 - a key player in microglial biology and Alzheimer disease. Nat Rev Neurol. 2018;14:667-75.

5. Fisher $A B$. Peroxiredoxin 6 in the repair of peroxidized cell membranes and cell signaling. Arch Biochem Biophys. 2017;617:68-83.

6. Li H, Benipal B, Zhou S, Dodia C, Chatterjee S, Tao JQ, Sorokina EM, Raabe T, Feinstein SI, Fisher AB. Critical role of peroxiredoxin 6 in the repair of peroxidized cell membranes following oxidative stress. Free Radic Biol Med. 2015;87:356-65

7. Patel P, Chatterjee S. Peroxiredoxin6 in Endothelial Signaling. Antioxidants (Basel). 2019:8

8. Asuni AA, Guridi M, Sanchez S, Sadowski MJ. Antioxidant peroxiredoxin 6 protein rescues toxicity due to oxidative stress and cellular hypoxia in vitro, and attenuates prion-related pathology in vivo. Neurochem Int. 2015;90: $152-65$.

9. Power JH, Asad S, Chataway TK, Chegini F, Manavis J, Temlett JA, Jensen PH, Blumbergs PC, Gai WP. Peroxiredoxin 6 in human brain: molecular forms, cellular distribution and association with Alzheimer's disease pathology. Acta Neuropathol. 2008;115:611-22.

10. Kuszczyk MA, Sanchez S, Pankiewicz J, Kim J, Duszczyk M, Guridi M, Asuni AA, Sullivan PM, Holtzman DM, Sadowski MJ. Blocking the interaction between Apolipoprotein E and Abeta reduces Intraneuronal accumulation of Abeta and inhibits synaptic degeneration. Am J Pathol. 2013;182:1750-68.

11. Sadowski M, Pankiewicz J, Scholtzova H, Ripellino JA, Li YS, Schmidt SD, Mathews PM, Fryer JD, Holtzman DM, Sigurdsson EM, Wisniewski T. A synthetic peptide blocking the apolipoprotein E/beta-amyloid binding mitigates beta-amyloid toxicity and fibril formation in vitro and reduces beta-amyloid plaques in transgenic mice. Am J Pathol. 2004;165:937-48.

12. Garcia-Alloza M, Robbins EM, Zhang-Nunes SX, Purcell SM, Betensky RA, Raju S, Prada C, Greenberg SM, Bacskai BJ, Frosch MP. Characterization of amyloid deposition in the APPswe/PS1dE9 mouse model of Alzheimer disease. Neurobiol Dis. 2006:24:516-24.

13. Jankowsky JL, Fadale DJ, Anderson J, Xu GM, Gonzales V, Jenkins NA, Copeland NG, Lee MK, Younkin LH, Wagner SL, et al. Mutant presenilins specifically elevate the levels of the 42 residue beta-amyloid peptide in vivo: evidence for augmentation of a 42-specific gamma secretase. Hum Mol Genet. 2004;13:159-70.

14. Wang Y, Phelan SA, Manevich Y, Feinstein SI, Fisher AB. Transgenic mice overexpressing peroxiredoxin 6 show increased resistance to lung injury in hyperoxia. Am J Respir Cell Mol Biol. 2006;34:481-6.

15. Phelan SA, Wang X, Wallbrandt P, Forsman-Semb K, Paigen B. Overexpression of Prdx6 reduces $\mathrm{H} 2 \mathrm{O} 2$ but does not prevent diet-induced atherosclerosis in the aortic root. Free Radic Biol Med. 2003:35:1110-20.

16. Fisher AB, Dodia C, Yu K, Manevich Y, Feinstein SI. Lung phospholipid metabolism in transgenic mice overexpressing peroxiredoxin 6. Biochim Biophys Acta. 1761;2006:785-92.

17. Wang X, Phelan SA, Petros C, Taylor EF, Ledinski G, Jurgens G, ForsmanSemb K, Paigen B. Peroxiredoxin 6 deficiency and atherosclerosis susceptibility in mice: significance of genetic background for assessing atherosclerosis. Atherosclerosis. 2004:177:61-70.

18. Wang X, Phelan SA, Forsman-Semb K, Taylor EF, Petros C, Brown A, Lerner CP, Paigen B. Mice with targeted mutation of peroxiredoxin 6 develop normally but are susceptible to oxidative stress. J Biol Chem. 2003;278:25179-90.

19. Burkholder T, Foltz C, Karlsson E, Linton CG, Smith JM. Health evaluation of experimental laboratory mice. Curr Protoc Mouse Biol. 2012;2:145-65.
20. Asuni AA, Guridi M, Pankiewicz JE, Sanchez S, Sadowski MJ. Modulation of amyloid precursor protein expression reduces beta-amyloid deposition in a mouse model. Ann Neurol. 2014;75:684-99.

21. Brahmachari S, Fung YK, Pahan K. Induction of glial fibrillary acidic protein expression in astrocytes by nitric oxide. J Neurosci. 2006;26:4930-9.

22. Livak KJ, Schmittgen TD. Analysis of relative gene expression data using real-time quantitative PCR and the 2(-Delta Delta C(T)) method. Methods. 2001;25:402-8

23. Sadowski MJ, Pankiewicz J, Scholtzova H, Mehta PD, Prelli F, Quartermain D, Wisniewski T. Blocking the apolipoprotein E/amyloid-beta interaction as a potential therapeutic approach for Alzheimer's disease. Proc Natl Acad Sci U S A. 2006;103:18787-92.

24. Schmidt SD, Jiang Y, Nixon RA, Mathews PM. Tissue processing prior to protein analysis and amyloid-beta quantification. Methods Mol Biol. 2005; 299:267-78

25. Pankiewicz JE, Guridi M, Kim J, Asuni AA, Sanchez S, Sullivan PM, Holtzman DM, Sadowski MJ. Blocking the apoE/A-beta interaction ameliorates A-betarelated pathology in APOE epsilon 2 and epsilon 4 targeted replacement Alzheimer model mice. Acta Neuropathol Commun. 2014:2:75.

26. Wisniewski HM, Sadowski M, Jakubowska-Sadowska K, Tarnawski M, Wegiel J. Diffuse, lake-like amyloid-beta deposits in the parvopyramidal layer of the presubiculum in Alzheimer disease. J Neuropathol Exp Neurol. 1998;57:674-83.

27. Pankiewicz JE, Baquero-Buitrago J, Sanchez S, Lopez-Contreras J, Kim J, Sullivan PM, Holtzman DM, Sadowski MJ. APOE genotype differentially modulates effects of anti-a beta, Passive Immunization in APP Transgenic Mice. Mol Neurodegener. 2017;12:12.

28. Braak H, Braak E. Demonstration of amyloid deposits and neurofibrillary changes in whole brain. Brain Pathol. 1991;1:213-6.

29. Cheng-Hathaway PJ, Reed-Geaghan EG, Jay TR, Casali BT, Bemiller SM, Puntambekar SS, von Saucken VE, Williams RY, Karlo JC, Moutinho M, et al. The Trem2 R47H variant confers loss-of-function-like phenotypes in Alzheimer's disease. Mol Neurodegener. 2018;13:29.

30. Ordonez-Gutierrez L, Fernandez-Perez I, Herrera JL, Anton M, Benito-Cuesta I, Wandosell F. AbetaPP/PS1 transgenic mice show sex differences in the cerebellum associated with aging. J Alzheimers Dis. 2016;54:645-56.

31. Wang J, Tanila H, Puolivali J, Kadish I, van Groen T. Gender differences in the amount and deposition of amyloidbeta in APPswe and PS1 double transgenic mice. Neurobiol Dis. 2003;14:318-27.

32. Sadowski MJ, Wisniewski T: Apoliporoteins in different amyloidoses. In Protein Misfolding, Aggregation, and Conformational Diseases. Edited by Uversky VN, Fink AL. Singapore: Springer; 2006: 101-122.[Atassi MZ (Series Editor): Protein Reviews].

33. Liddelow SA, Barres BA. Reactive astrocytes: production, function, and therapeutic potential. Immunity. 2017:46:957-67.

34. Liddelow SA, Guttenplan KA, Clarke LE, Bennett FC, Bohlen CJ, Schirmer L, Bennett ML, Munch AE, Chung WS, Peterson TC, et al. Neurotoxic reactive astrocytes are induced by activated microglia. Nature. 2017:541:481-7.

35. Yun SP, Kam TI, Panicker N, Kim S, Oh Y, Park JS, Kwon SH, Park YJ, Karuppagounder SS, Park H, et al. Block of A1 astrocyte conversion by microglia is neuroprotective in models of Parkinson's disease. Nat Med. 2018:24:931-8.

36. Wang Y, Ulland TK, Ulrich JD, Song W, Tzaferis JA, Hole JT, Yuan P, Mahan TE, Shi Y, Gilfillan S, et al. TREM2-mediated early microglial response limits diffusion and toxicity of amyloid plaques. J Exp Med. 2016;213:667-75.

37. Gowrishankar S, Yuan P, Wu Y, Schrag M, Paradise S, Grutzendler J, De Camilli P, Ferguson SM. Massive accumulation of luminal protease-deficient axonal lysosomes at Alzheimer's disease amyloid plaques. Proc Natl Acad Sci U S A. 2015:112:E3699-708.

38. De Strooper B, Karran E. The cellular phase of Alzheimer's disease. Cell. 2016; 164:603-15.

39. Wisniewski HM, Wegiel J. Spatial relationships between astrocytes and classical plaque components. Neurobiol Aging. 1991;12:593-600.

40. Bannitz-Fernandes R, Aleixo-Silva R, Silva JP, Dodia C, Vazquez-Medina JP, Tao JQ, Fisher A, Netto L. Non-Mammalian Prdx6 Enzymes (Proteins with 1Cys Prdx Mechanism) Display PLA(2) Activity Similar to the Human Orthologue. Antioxidants (Basel). 2019:8

41. Manevich Y, Reddy KS, Shuvaeva T, Feinstein SI, Fisher AB. Structure and phospholipase function of peroxiredoxin 6 : identification of the catalytic triad and its role in phospholipid substrate binding. J Lipid Res. 2007:48: 2306-18. 
42. Cheignon C, Tomas M, Bonnefont-Rousselot D, Faller P, Hureau C, Collin F. Oxidative stress and the amyloid beta peptide in Alzheimer's disease. Redox Biol. 2018;14:450-64.

43. Manevich Y, Shuvaeva T, Dodia C, Kazi A, Feinstein SI, Fisher AB. Binding of peroxiredoxin 6 to substrate determines differential phospholipid hydroperoxide peroxidase and phospholipase a(2) activities. Arch Biochem Biophys. 2009;485:139-49.

44. Chatterjee S, Feinstein SI, Dodia C, Sorokina E, Lien YC, Nguyen S, Debolt K, Speicher D, Fisher AB. Peroxiredoxin 6 phosphorylation and subsequent phospholipase A2 activity are required for agonist-mediated activation of NADPH oxidase in mouse pulmonary microvascular endothelium and alveolar macrophages. J Biol Chem. 2011;286:11696-706.

45. Ambruso DR, Ellison MA, Thurman GW, Leto TL. Peroxiredoxin 6 translocates to the plasma membrane during neutrophil activation and is required for optimal NADPH oxidase activity. Biochim Biophys Acta. 1823;2012:306-15.

46. Fukai T, Ushio-Fukai M. Superoxide dismutases: role in redox signaling, vascular function, and diseases. Antioxid Redox Signal. 2011;15:1583-606.

47. Ushio-Fukai M. Compartmentalization of redox signaling through NADPH oxidase-derived ROS. Antioxid Redox Signal. 2009;11:1289-99.

48. Lassegue B, Griendling KK. NADPH oxidases: functions and pathologies in the vasculature. Arterioscler Thromb Vasc Biol. 2010;30:653-61.

49. Go YM, Jones DP. Cysteine/cystine redox signaling in cardiovascular disease. Free Radic Biol Med. 2011;50:495-509.

50. Bogdan C, Rollinghoff M, Diefenbach A. Reactive oxygen and reactive nitrogen intermediates in innate and specific immunity. Curr Opin Immunol. 2000;12:64-76

51. Huang J, Canadien V, Lam GY, Steinberg BE, Dinauer MC, Magalhaes MA, Glogauer M, Grinstein S, Brumell JH. Activation of antibacterial autophagy by NADPH oxidases. Proc Natl Acad Sci U S A. 2009;106:6226-31.

52. Schmitt A, Schmitz W, Hufnagel A, Schartl M, Meierjohann S. Peroxiredoxin 6 triggers melanoma cell growth by increasing arachidonic acid-dependent lipid signalling. Biochem J. 2015;471:267-79.

53. Arevalo JA, Vazquez-Medina JP. The Role of Peroxiredoxin 6 in Cell Signaling. Antioxidants (Basel). 2018:7

54. Su F, Bai F, Zhou H, Zhang Z. Microglial toll-like receptors and Alzheimer's disease. Brain Behav Immun. 2016;52:187-98.

55. Gambuzza ME, Sofo V, Salmeri FM, Soraci L, Marino S, Bramanti P. Toll-like receptors in Alzheimer's disease: a therapeutic perspective. CNS Neurol Disord Drug Targets. 2014;13:1542-58.

56. Frakes $A E$, Ferraiuolo L, Haidet-Phillips AM, Schmelzer L, Braun L, Miranda CJ, Ladner KJ, Bevan AK, Foust KD, Godbout JP, et al. Microglia induce motor neuron death via the classical NF-kappaB pathway in amyotrophic lateral sclerosis. Neuron. 2014;81:1009-23.

57. Chen WT, Lu A, Craessaerts K, Pavie B, Sala Frigerio C, Corthout N, Qian X, Lalakova J, Kuhnemund M, Voytyuk I, et al. Spatial Transcriptomics and In Situ Sequencing to Study Alzheimer's Disease. Cell. 2020;182:976-991 e919.

58. Sala Frigerio C, Wolfs L, Fattorelli N, Thrupp N, Voytyuk I, Schmidt I, Mancuso R, Chen WT, Woodbury ME, Srivastava G, et al. The major risk factors for Alzheimer's disease: age, sex, and genes modulate the microglia response to Abeta plaques. Cell Rep. 2019;27:1293-306 e1296.

59. Jay TR, von Saucken VE, Landreth GE. TREM2 in neurodegenerative diseases. Mol Neurodegener. 2017;12:56.

60. Yun HM, Jin P, Han JY, Lee MS, Han SB, Oh KW, Hong SH, Jung EY, Hong JT. Acceleration of the development of Alzheimer's disease in amyloid betainfused peroxiredoxin 6 overexpression transgenic mice. Mol Neurobiol. 2013;48:941-51.

61. Yun HM, Choi DY, Oh KW, Hong JT. PRDX6 exacerbates dopaminergic Neurodegeneration in a MPTP mouse model of Parkinson's disease. Mol Neurobiol. 2015:52:422-31.

62. Kraft AW, Hu X, Yoon H, Yan P, Xiao Q, Wang Y, Gil SC, Brown J, Wilhelmsson $U$, Restivo $J$, et al. Attenuating astrocyte activation accelerates plaque pathogenesis in APP/PS1 mice. FASEB J. 2013;27:187-98.

63. Drummond E, Nayak S, Faustin A, Pires G, Hickman RA, Askenazi M, Cohen M, Haldiman T, Kim C, Han X, et al. Proteomic differences in amyloid plaques in rapidly progressive and sporadic Alzheimer's disease. Acta Neuropathol. 2017;133:933-54.

\section{Publisher's Note}

Springer Nature remains neutral with regard to jurisdictional claims in published maps and institutional affiliations.

Ready to submit your research? Choose BMC and benefit from:

- fast, convenient online submission

- thorough peer review by experienced researchers in your field

- rapid publication on acceptance

- support for research data, including large and complex data types

- gold Open Access which fosters wider collaboration and increased citations

- maximum visibility for your research: over $100 \mathrm{M}$ website views per year

At BMC, research is always in progress.

Learn more biomedcentral.com/submissions 